Rhode Island College

Digital Commons @ RIC

\title{
Nurse Practitioner Perspectives on the Barriers and Facilitators of Advance Care Planning
}

Cherish Dellava

Rhode Island College

Follow this and additional works at: https://digitalcommons.ric.edu/etd

Part of the Nursing Commons

\section{Recommended Citation}

Dellava, Cherish, "Nurse Practitioner Perspectives on the Barriers and Facilitators of Advance Care Planning" (2017). Master's Theses, Dissertations, Graduate Research and Major Papers Overview. 185.

https://digitalcommons.ric.edu/etd/185

This Major Paper is brought to you for free and open access by the Master's Theses, Dissertations, Graduate Research and Major Papers at Digital Commons @ RIC. It has been accepted for inclusion in Master's Theses, Dissertations, Graduate Research and Major Papers Overview by an authorized administrator of Digital Commons @ RIC. For more information, please contact digitalcommons@ric.edu. 
NURSE PRACTITIONER PERSPECTIVES ON THE BARRIERS AND

\title{
FACILITATORS OF ADVANCE CARE PLANNING
}

\author{
by
}

\section{Cherish Dellava}
A Major Paper Submitted in Partial Fulfillment of the Requirements for the Degree of
Master of Science in Nursing
in

The School of Nursing

Rhode Island College 



\begin{abstract}
Every year, thousands of residents in the United States die while receiving end of life (EOL) care that is inconsistent with their wishes. Research evidence has shown that advance care planning (ACP) improves congruity between patients' preference and actual care received at EOL. Despite medical guidelines supporting ACP, these discussions rarely occur. The purpose of this study was to explore the perspectives of nurse practitioners (NPs) on the barriers and facilitators of ACP. The web-based ACP survey was distributed to the members of the New Hampshire Nurse Practitioner Association (NHNPA). The participants $(\mathrm{n}=65)$ were mostly women $(96.9 \%)$, had a Master's degree (83.1\%), and had 16 to 25 years of practice as NPs (37.5\%). Results indicated that the most common barriers to ACP were related to time including type of appointment, lack of time, and length of appointment. The most common facilitators were personal experience, comfort with the topic, long-term relationship with the patient, and previous education and training. Implications for advance nursing practice include conducting research on the patients' perspective on ACP, and development of evidence-based tools and methods to facilitate ACP discussions. Improving education and training of healthcare providers on ACP and EOL care issues, increasing advocacy for payment and scheduling systems that facilitate $\mathrm{ACP}$, supporting policies that require ACP to patients with chronic, progressive or terminal conditions, and improving public awareness of ACP are recommended.
\end{abstract}




\section{Acknowledgements}

Overcoming this feat would not have been possible without an army of people who has inspired and motivated me. I would like to express my gratitude to the following:

Professor Linda Dame for her guidance, patience and wisdom. Your encouragement has kept me going. Thank you for your dedication and genuine regard for my project and my well-being.

Bonnie Evans and Kara Doberstein for sharing your time, knowledge and expertise.

Ashley Chartier, you are one of the best blessings I have ever received. I know meeting you on our first class in graduate school was not an accident. Your presence has lightened my burdens and has made the toughest challenges surmountable. You have inspired me to be the best I can be, and you have led me to believe that there is no better armor in a long and arduous journey than a friend.

Joe, my partner through it all. In you, I find shelter through the greatest tempest and joy in the mundane. Whether I come home in victory or defeat, you have made it clear that you are there to love me through all of life's seasons. I love you with all that I am, and I am immeasurably grateful for the gift of being married to you.

My parents and siblings who believed in my potential and endlessly encouraged, inspired and motivated me to give my best. Thank you for the constant reassurance that I am enough — such a simple gesture yet so powerful. Thank you for your steadfast love. You have given me the courage and confidence to conquer my dreams. 
To God, from whom all blessings flow, my heartfelt gratitude for giving me a dream to pursue, the strength to endure, faith to persevere, wisdom to guide me, and the power to overcome. 


\section{Table of Contents}

Background/Statement of the Problem ..................................................................... 1

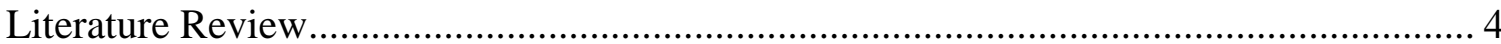

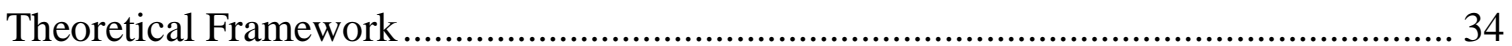

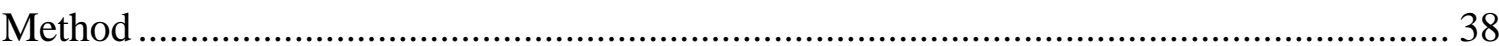

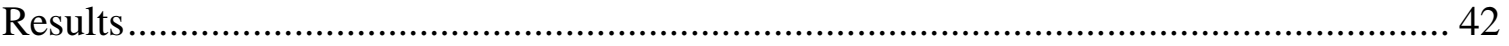

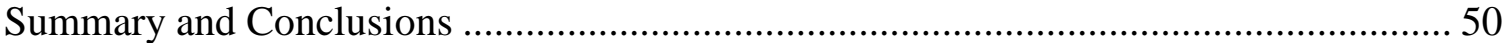

Recommendations and Implications for Advanced Nursing Practice ............................. 55

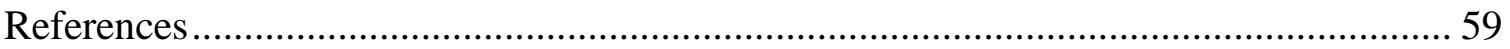

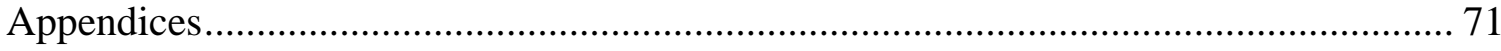




\section{NURSE PRACTITIONER PERSPECTIVES ON THE BARRIERS AND FACILITATORS OF ADVANCE CARE PLANNING}

\section{Background/Statement of the Problem}

Every year, thousands of residents in the United States (U.S.) die while receiving care that is contrary to their wishes. End of life discussions with patients dealing with a terminal illness are often delayed and do not occur until the patient is actively dying, thus hindering the processes that can facilitate a 'good death'. A good death is defined as one that is free from avoidable suffering and is in accordance with the wishes of patients and families (Field \& Cassel, 1997).

According to a survey by the Dartmouth Atlas of Health Care (2012), 80 percent of patients with chronic illness state that they want to avoid hospitalization and intensive care during the terminal phase of the disease. Research shows an increase in multiple hospitalizations in the last few months of life, and an increase in intensive care services, which suggests an increase in intensity and aggressiveness of care at the EOL (Riley \& Lubitz, 2010). In 2014, 37\% of deaths occurred in the hospital (Centers for Disease Control and Prevention [CDC], 2016). These research data reveals evidence of incongruence between patient preference and actual care received at the EOL.

Advance care planning has been shown to increase concordance between patients' preferences and care received at the EOL (Detering, Hancock, Reade, \& Silvester, 2010). Advance care planning has been associated with decreased aggressive medical interventions near death, better quality of life scores and increased utilization of palliative or hospice care resources (Detering et al., 2010; Wright et al., 2008). Patients who had ACP discussion are more likely to accept that their illness is terminal and more likely to choose comfort care and a do-not-resuscitate order (DNR) (Wright et al., 2008). 
Advance care planning was also associated with fewer symptoms of posttraumatic stress disorder, depression and anxiety among family members and caregivers of the decedents (Detering et al., 2010). The aforementioned effects of ACP on patients and caregivers are consistent with foundational themes associated with a 'good death' or successful dying' (Meier et al., 2016).

The Institute of Medicine (IOM), American Association of Critical Care Nurses, and American Association of Colleges of Nursing have endorsed ACP as an integral part of patient-centered care. Shared decision-making between patient and provider is the hallmark of patient-centered care. Nurse Practitioners (NPs) in the primary and acute care settings are expected to provide care throughout a care continuum, from care of chronic illness to stabilization of acute conditions to restoration of health to provision of palliative, supportive and EOL care (American Association of Critical Care Nurses, 2012; American Association of Colleges of Nursing, 2010). The IOM emphasizes the critical role of ACP on quality EOL care by ensuring that patients' preferences and needs are met (2014). Despite medical guidelines and research evidence supporting ACP discussion, these discussions rarely occur (Keary \& Moorman, 2015).

Discussions about EOL care preferences are more relevant now than ever as the elderly population in the U.S. continue to rise. By 2030, all baby boomers will be over 65 years old, accounting for more than 20 percent of the U.S population (Colby \& Ortman, 2015). A rapidly rising older adult population increases the need for healthcare providers to initiate timely and regular ACP discussions. However, uptake of ACP in healthcare organizations and in individual practice has been limited (Lund, Richardson \& May, 2015). Improving practice and frequency of ACP requires inquiry into the 
personal, professional and systems-specific factors that influence behavior of health care professionals.

Even though numerous studies on ACP have been undertaken, these studies are focused on physician perspectives, and there is a clear paucity of research done to explore NP perspectives. Exploring the perspectives of NPs on the barriers and facilitators of ACP discussion is critical to improve the practice. Therefore, the purpose of this study is to explore NP perspectives on the barriers and facilitators of ACP. 


\section{Literature Review}

A literature search was conducted in CINAHL, Pub Med, Brown Library, Google Scholar and Medline databases using key words: end of life discussion; end of life care; advance care planning; history of end of life care; care of the dying; barriers to advance care planning or end of life discussion. Combinations of concepts were also used including the words advance care planning or end of life discussion, and perspectives of: patients or providers or caregivers.

Literature used for this review was limited from the year 2000 to present. Select relevant articles from 1906 to present were included to elucidate a clear historical picture of EOL care and ACP. The terms ACP and EOL care discussion will be used interchangeably throughout this study.

\section{End of Life Care: Definition and History}

According to the IOM report Dying in America, EOL care is defined as the "processes of addressing the medical, social, emotional, and spiritual needs of people nearing the end of life" (2014, p. 27). End of life care in the U.S. is an evolving process that reflects the perceptions, values, and medical advances in certain points in history. In the early 1900s, life expectancy in the U.S. was 47 years (CDC, 2010a). Death was usually sudden after a short illness. Family members cared for the dying at their home (Lowey, 2015). Death was omnipresent with little or no treatment available once a person became ill. In the year 1900 , the mortality rate was 17.6 per 1,000 persons, and the most common cause of death was due to infectious diseases such as typhoid fever, smallpox and tuberculosis (CDC, 1906). These mortality rates are significantly higher compared to current mortality rates 8.2 per 1,000 populations (CDC, 2013). 
In the second half of the $20^{\text {th }}$ century, new science and medical technology offered treatments that shifted the goals of care from comfort care to curative treatments (Lowey, 2015). Formal medical and nursing training arose, and hospitals increased in number. The sick were cared for in the hospital and less people died at home. As science and medicine evolved with newer medications and treatments, the U.S. saw an increase in life expectancy and a decrease in mortality rates (Lowey, 2015). The increase in life expectancy and prevalence of chronic illnesses has changed the trajectory of dying to a longer and more complex process (Old, 2008).

Towards the end of the twentieth century, palliative care began to evolve as a distinct specialty within nursing and medicine in response to an aging population dealing with life-limiting illnesses. Palliative care emerged from the hospice movement, providing specialized care to the dying (Giovanni, 2012). Today, palliative care provides specialized care to patients and families facing physical, psychosocial and spiritual problems associated with life-threatening illness (World Health Organization, n.d.); expanding the scope of care while espousing the basic principles of hospice care (Giovanni, 2012).

\section{Definition of Advance Care Planning and End-of-Life Care Discussion}

Advance care planning is an ongoing process of communication between the patient and provider to clarify values and goals of care, and preferences for EOL care (IOM, 2014). The process of ACP should ideally occur with the patient, the patient's health care agent and the healthcare provider (IOM, 2014). Content of ACP discussions are then recorded in written documents or medical orders. Outcomes of ACP discussion includes designation of a healthcare proxy, code status decisions, living will, advance 
directives and medical orders but the focus is on the process, that is, the communication of values and preferences to guide future medical decision-making, rather than the mere completion of an advance directive form (Sabatino, 2010).

End of life discussion is defined as the conversation between patient and healthcare provider on preference or wishes for EOL care, preferences regarding resuscitation and code status, completion of advance directives, designation of health care proxy and decisions on comfort or palliative care or hospice (Myers, 2015). According the Myers (2015), there is no clear distinction between ACP and EOL discussion.

\section{What is a 'Good Death'?}

In the IOM report Approaching Death, a good death is defined as "one that is free from avoidable distress and suffering for patients, families, and caregivers; in general accord with patients' and families' wishes; and reasonably consistent with clinical, cultural, and ethical standards" (Field \& Cassel, 1997, p. 4). A systematic review by Meier et al. (2016) was conducted to uncover what a good death or successful dying means from the perspectives of patients, families and healthcare providers. The researchers selected 36 relevant articles; 27 qualitative studies, 5 quantitative studies and 4 mixed methods studies. The study participants included patients, pre-bereaved and bereaved family members, and health care providers. Common themes and subthemes were identified. The most frequently mentioned themes across all groups were preferences for the dying process and being pain-free. Preferences for the dying process included how, when and where the patient died, death occurring during sleep and having previous preparations for death such as presence of an advance directive. 
According to the patient perspective, a good death entails life completion, enactment of treatment preferences, dignity and family. The theme of life completion included subthemes such as being able to say goodbye, contentment with how life was lived and acceptance of terminal illness. Satisfaction with treatment preferences includes subthemes such as not prolonging life, having a sense of control over treatment, belief that all available treatments were used, and availability of euthanasia or physician assisted suicide. Dignity was described as being respected and maintaining independence. The theme of family contained subthemes such as family support, family acceptance for the death and not being a burden to family (Meier et al., 2016).

Themes of a good death reported by family members were the preference for the dying process, being pain-free and life completion. The most common themes among health care providers were preference for the dying process, pain-free status, dignity and emotional well-being (Meier et al., 2016). The systematic review provided insight into what is most important to patients and families in the dying process. Understanding their goals and values is an essential step to providing patient-centered care. Themes on patient perspectives such as acceptance of death, sense of control over treatment, respect as an individual, and family acceptance for death are consistent with the goals of ACP.

\section{Current Conditions of End of Life Care}

As Americans live longer, the multiplicity of chronic conditions continue to rise and Medicare spending for patients with chronic illness, especially in their last years, continues to escalate. Fourteen percent of American residents who have chronic conditions and functional limitations account for $56 \%$ of healthcare costs (IOM, 2014). Thirty-two percent of total Medicare spending is utilized for patients with chronic 
illnesses in the last two years of life, with majority of payments going towards physician fees and repeated hospitalizations (Dartmouth Atlas of Health Care, 2016). Long-term trends in Medicare payment have shown that $25 \%$ of Medicare expenditures are for health care during the last year of life (Riley \& Lubitz, 2010). Riley \& Lubitz (2010) studied data that demonstrated an increase in multiple hospitalizations in the last few months of life and an increase in intensive care services, which suggests an increase in intensity and aggressiveness of care at the EOL. In 2007, $17.6 \%$ of deaths occurred in the intensive care unit (ICU) and patients spent an average of 10.9 days in the hospital in the last six months of life (Goodman, Esty, Fisher, \& Chang, 2011), and 36\% of all deaths occurred in the inpatient hospital setting (CDC, 2010b). In the U.S. when the patient's wishes are not known or documented in advance, the default course of action is to start or continue life sustaining treatment, which can result in more aggressive care at the EOL.

Statistical reports of aggressive care at the EOL are incongruent with research evidence on patients' EOL care preferences. According to the Dartmouth Atlas of Health Care (2012), 80 percent of patients with chronic illness state that they want to avoid hospitalization and intensive care during the terminal phase of the disease. Preference to die at home has been widely reported in literature (Billingham, \& Billingham, 2013; Stajduhar, Allan, Cohen \& Heyland, 2008).

Patient preference to avoid aggressive care was also reflected in a study by Barnato et al., (2007). The researchers conducted a survey on 2,515 Medicare beneficiaries to determine regional differences in EOL treatment intensity and preferences for EOL care. The respondents were asked general preferences for medical 
care in the event of a serious illness or a prognosis of less than 1 year. The analysis revealed that $86 \%$ of the respondents preferred to die at home if they were faced with a terminal illness, compared to $9.1 \%$ who wanted to die in a hospital and $4.9 \%$ who wanted to die in a nursing home. Barnato et al. (2007) also revealed that $84 \%$ of respondents did not want life-prolonging drugs that may make them feel worse, $71.7 \%$ preferred palliative drugs even if those drugs may shorten life, and $77.4 \%$ did not want mechanical ventilation even if it were to extend life to one month.

Heyland et al. (2013) also revealed patient preference for comfort care or medical care that does not include resuscitation. Heyland et al. (2013) sought to determine prevalence of ACP and preference of care from the patient and family members' perspectives, and to assess documentation of EOL care preferences in the medical record. The researchers recruited elderly patients who were at risk of dying in the next 6 months and their family members. The study participants included 278 patients and 225 family members. The researchers revealed that $47.9 \%$ of patients reported having an advance care plan and $73.3 \%$ had a surrogate decision maker. Thirty percent of patients preferred comfort care and $30.6 \%$ preferred a mix of comfort care and full medical care that does not include resuscitation. Family members shared the same perspective, as $34.8 \%$ preferred comfort care and $27.7 \%$ preferred comfort care and full medical care without resuscitation. According to the researchers, patient preference and documentation of goals of care were congruent in only $30.2 \%$ of the participants. Of the patients who reported a preference for comfort care only, documentation of this preference was found in only $4.5 \%$ of medical records. The researchers also revealed that $17 \%$ of patients and $18.2 \%$ of family members had discussed their preferences with a family physician which 
may explain the incongruity between preference for care and preference actually documented in the medical record.

\section{Decision making capacity at end of life.}

Evidence of incapacity to make EOL treatment decisions may contribute to the incongruence between patient preference and actual EOL care. Silveira, Kim \& Langa (2010) conducted a study to determine prevalence of the need for medical decision making at the EOL and lost decision-making capacity of decedents 60 years or older at the time of death. Data were obtained through an exit interview of the decedents' health care proxies 24 months after the subject's death. The researchers found that $42.5 \%$ or 1,536 decedents needed to make decisions about treatments at the EOL and of these subjects, $70.3 \%$ lacked decision-making capacity. The researchers also found that those decedents with a living will or health care proxy were less likely to die in the hospital, and more likely to receive limited care and comfort care compared to those without a living will or health care proxy.

A systematic review was conducted by Sessums, Zembrzuska and Jackson (2011) to determine the prevalence of incapacity in adult medicine patients without severe mental illness. Twenty-five prospective studies that documented prevalence of incapacity were included in the systematic review. The researchers found that $44 \%(95 \%$ CI, 28\%-60\%) of nursing home residents and 26\% (95\% CI, 18\%-35\%) of hospitalized patients lacked decision-making capacity (Sessums et al., 2011).

Sorger, Rosenfeld, Pressin, Timm and Cimino (2007) explored the decisionmaking capacity and cognitive functioning among elderly, terminally ill patients with cancer and elderly, physically healthy adults from a supportive community residence. 
The terminally ill sample were recruited from a palliative care hospital, had end-stage cancer and had a life expectancy of less than 6 months. The Hopkins Competency Assessment Test was used to test competence to provide informed consent. The measures used to assess for cognitive functioning were the Mini-Mental State Exam, the Concept Assessment Kit and the Bechara Gambling Task. The researchers found that $44.2 \%$ of the terminally ill participants had inadequate decision-making capacity compared to only $5.9 \%$ of the healthy sample. The results highlight the significant prevalence of impairment in decision-making capabilities among those who are terminally ill and the cognitive competence of the healthy elderly. The evidence supports the occurrence of ACP discussions well before a patient experiences a decline in health status.

\section{The shortcomings of advance directives.}

Although advance directives, such as living wills and durable power of attorney documents, increased congruence between patient preference and actual EOL care compared to those who did not have such documents, evidence of the shortcoming of advance directives continue to emerge. Nauck et al. (2014) conducted a qualitative study on patients' preferences verbally expressed during an interview and its congruence to what is written on their advance directives. Fifty-three participants, age 55 to 70 years old, with an advance directive were interviewed using a semi structured interview guide. The researchers found incongruities in more than half of the participants' advance directives and their verbally expressed wishes. Forty-seven percent of the participants used a standardized form and narrative sections were filled with nonspecific phrases such as "I want to die with dignity" which could be misinterpreted by health care proxies or 
health care providers. The lack of individualization of advance directives prevent the full disclosure of patients' values and wishes, and the lack of involvement of medical providers makes the patient ill equipped to make a fully informed decision.

Winter, Parks \& Diamond (2010) sought to assess the association between answers to standard living will questions and responses to poor-health scenarios. Two hundred-two participants, 70 years of age or older, were recruited for the study. A standardized telephone interview was conducted and included standard living will questions such as "would you direct your physician to withdraw or withhold lifesustaining treatment that serves only to prolong the process of dying, if you should be in a terminal condition or in a state of permanent unconsciousness?" (p. 568). Questions on life-sustaining treatment preferences were asked on six poor-health scenarios. At most, there was a $23 \%$ variance between responses on the living will and treatment preferences questions. The most variance was seen in scenario-based preferences that were not clearly explained on the standard living will questions. These results highlight the inadequacy of standard living will questions to approximate most EOL scenarios. Furthermore, this study supports the need to regularly review EOL care preferences and update living will information over time, and as an individual's health status changes.

A prospective study by Ditto, Jacobson, Smucker, Danks, and Fagerlin (2006) sought to examine the desire for life-sustaining medical treatment among elderly adults prior to, soon after, and several months after hospitalization. Data from the Advance Directives, Values Assessment and Communication Enhancement (ADVANCE) project was used. Of the 103 eligible participants, 88 participants ranging from 65 to 94 years old completed the prehospitalization, recovery, and post-hospitalization interviews. 
During the interviews, the participants were given the Life-Support Preferences Questionnaire (LPSQ), which assess patients' desire for medical treatment in various health scenarios. Medical treatments include cardiopulmonary resuscitation (CPR) for cardiac arrest, artificial nutrition and hydration (ANH), gallbladder surgery for a lifethreatening gallbladder infection, and antibiotics for life-threatening pneumonia. Repeated-measure analyses of variance were used to compare mean desire for treatment across the 3 interviews. The researchers found significant changes in the mean LPSQ scores across the 3 interviews (prehospitalization $\mathrm{M}=2.21$, recovery $\mathrm{M}=1.98$, posthospitalization $\mathrm{M}=2.09$ ). The preference for $\mathrm{CPR}$ and $\mathrm{ANH}$ showed a "hospitalization dip' wherein the participants expressed less desire for receiving each treatment immediately after hospitalization. According to the researchers, this suggests that individual preferences for life-sustaining treatment vary over time and across changes in medical condition. The researchers assert that an advance directive is unable to capture individual preferences over time, and recommended a continuous process of determining and documenting patient's wishes and values.

The process of ACP arose in response to the shortcomings of advance directives to direct complex medical decision-making in EOL care (IOM, 2014). Advance care planning has been shown to increase concordance between patients' preferences and care received at the EOL. Detering et al. (2010) conducted a prospective randomized control trial to examine the impact of ACP on EOL care received by elderly patients. Three hundred nine participants, age 80 years or older, were randomized to the usual care group or the usual care plus ACP group. Compliance with EOL wishes was determined through interviews with family members of the participants who had died and review of medical 
records. Six months after randomization, 29 of the 154 participants in the intervention group and 27 of the 155 participants in the control group had died. The researchers revealed that EOL wishes were known and followed in 25 of $29(86 \%)$ of patients in the intervention group compared to 8 of 27 patients (30\%) in the control group. The family members of the decedents in the intervention group were more likely to have positive responses on the patient satisfaction surveys (76\%) compared to those in the control group (18.5\%). Family members of the decedents in the intervention group also reported fewer symptoms of post-traumatic stress, depression and anxiety, and were more likely to report being very satisfied with the quality of death (83\%) compared to the control group $(48 \%)$

\section{Advance Care Planning and the Patient}

The majority of older patients with chronic illness, viewed ACP as a valuable part of medical care, desired to have an ACP discussion with their providers, and expressed that ACP gives them a sense of empowerment (Davison, 2006; Burge et al., 2013). However, ACP occurs infrequently. Keary and Moorman (2015) conducted a large study to determine the prevalence of ACP in the routine care of Medicare beneficiaries. The researchers revealed that of the 5,199 participants, less than $1 \%$ (310) reported having any ACP discussion with their physicians.

Rao, Anderson, Lin and Laux (2014) conducted a survey to determine the completion rate of advance directives among U.S. consumers and to determine the factors that are associated with its completion. The study had a total of 7,949 respondents. Sixtyeight percent respondents reported of having concerns about EOL care, however, only $26.3 \%(2,093)$ had advance directives. Forty-eight percent reported of having EOL 
discussion with others. Of the respondents who reported that they had an advance directive, only $44.1 \%$ had EOL discussion with others. Lack of awareness was the most commonly reported reason for not having an advance directive. Advance directive completion rates were higher in respondents who were 55 years or older, White, had a higher level of education, and higher income (Rao et al., 2014). The study did not specifically address whether EOL discussion occurred with their physician. The authors also disclosed a possible selection bias as the respondents were mostly community dwelling adults, and response may represent those who may have had an interest in EOL issues.

A study by Bischoff, Sudore, Miao, Boscardin and Smith (2013) sought to determine the influence of ACP on quality of EOL care. The study population consisted of 4,394 decedents from the Health and Retirement Study cohort. Data was obtained from their healthcare proxy within 24 months after death. Eighty percent of the study population were 75 years and older. The study revealed that $76 \%$ of the decedents had an advance directive, durable power of attorney, ACP discussion, or all three components of ACP. However, only $26 \%$ of all decedents had all three components of ACP. The authors found that the decedents with an advance directive, durable power of attorney, or ACP discussion had lower rates of in-hospital death and higher hospice enrollment. However, the researchers found no significant difference in the rate of hospitalization, ICU admission and frequency of Emergency Department visits in the last month of life. Mean time from advance directive completion to death was 61 months. The authors postulate that neither ACP documents nor ACP discussion alone may be adequate in capturing the patient's EOL wishes. A multimodal approach to ACP that includes 
completion of ACP documents and regular ACP discussion is recommended to fully assess and document the patients' EOL wishes over time (Bischoff, et al., 2013).

Mack, Weeks, Wright, Block and Prigerson (2010) conducted a longitudinal, multi-institutional cohort study to evaluate factors that affect EOL care that is consistent with patient preference. The researchers reported that only $39 \%$ of patients with terminal cancer stated having any EOL care discussion with their providers. The researchers also found that EOL care discussion with a physician was associated with care consistent with patient preference $(P=.005)$.

\section{Effects of advance care planning on the patient and caregivers.}

Advance care planning has been associated with decreased aggressive medical interventions near death, better quality of life scores and increased utilization of palliative or hospice care resources (Detering et al., 2010; Wright et al., 2008). A study by Wright et al. (2008) sought to determine associations between EOL care discussions with physicians and medical interventions received at the EOL. The researchers reported that $123(37 \%)$ of the 332 participants reported having EOL discussions with their physicians. Patients who received EOL discussions had lower rates of mechanical ventilation, resuscitation, ICU admission and earlier hospice enrollment compared to those who did not have any EOL discussion. The researchers also reported that caregivers of patients who received aggressive care at the EOL had a higher risk for developing major depression (adjusted odds ratio, 3.37; 95\% confidence interval), expressing a sense of regret $(\mathrm{P}=.01)$ and unpreparedness for patient's death $(P<.001)$. In this study, aggressive care of a loved one at the EOL, had the potential to negatively impact caregivers. 
Timing of EOL care discussion impacts treatment received at the EOL. Oncology patients who had EOL care discussions at least 30 days before death were less likely to receive aggressive care, had lower rates of hospitalizations, lower rates of chemotherapy in the last 14 days, lower likelihood of dying in the hospital and fewer invasive procedures (Doll et al., 2013; Lopez-Acevedo et al., 2013; Wright et al., 2008). Wright et al. (2008) explained that the associations between EOL care discussion and less aggressive care may be that patients who reported having EOL discussions were more likely to accept that their illness was terminal and more likely to choose comfort care and have a DNR order. This research evidence further supports the initiation of ACP discussions earlier in the disease process and as part of routine care.

Conversely, patients who did not have EOL care discussions received more aggressive care, were more likely to spend less than 1 week in hospice care, and had lower quality of life scores (Wright et al., 2008). Patients who were enrolled in hospice for less than one week had the same quality of life score as those who did not receive hospice care at all. This trend towards shorter hospice length of stay ensues. According to the National Hospice and Palliative Care Organization (2015), majority of hospice patients (35.5\%) in 2014 had an average length of service of 7 days or less.

\section{Patient perspectives on barriers to advance care planning.}

A survey by the Conversation Project (2013) showed that 90\% of Americans think that they should have conversations about their EOL care wishes but only $30 \%$ have had these conversations. A descriptive study by Schickedanz et al. (2009) was conducted to explore patient's self-identified barriers to ACP. The most common barriers to ACP according to respondents were: $\mathrm{ACP}$ is thought to be irrelevant (perceive themselves as 
healthy or want to leave it up to fate or God); personal barriers such as work and family responsibilities or ACP makes them emotional; relationship concerns such as poor or no relationship with family, friends or physician; time constraints during health encounters with physician; and problems with advance directives.

\section{History of Advance Care Planning and Policy}

ACP has been an evolving concept that was conceived to address the medical and ethical issues surrounding EOL care, particularly the growing awareness of unwanted aggressive care, and the exercise of patient autonomy. Luis Kutner, a human rights lawyer, proposed the concept of advance directives in 1969 (Sabatino, 2010). According to Luis Kutner, a person of sound mind should indicate in writing the extent of treatment that he would like to receive specifically, to withhold artificial life support systems in specific instances e.g. terminal illness (Kutner, 1969). Kutner called this document a "living will" which he described as a "declaration for bodily autonomy" and "a declaration determining the termination of life" (Kutner, 1969). According to Kutner (1969), the living will is a document that would indicate the extent to which the patient wishes to allow or withhold life-sustaining treatment. The living will could also document preferences for care for religious reasons such as refusal of blood transfusions for patients of the Jehovah's Witness faith (Kutner, 1969).

It was not until 1976 when the first bill to legally sanction living wills was passed in California (Sabatino, 2010). Living will legislations were slowly adopted by other states, owing in part to the Karen Ann Quinlan case that catapulted right-to-die issues and the importance of living will to mainstream media (Martyn \& Jacobs, 1984). By 1988, 38 other states enacted living will laws (Glick \& Hays, 1991). 
The limitations of the living will became apparent as it only applies to life sustaining treatment and the ambiguity of "extraordinary measures" is legally and morally problematic (Martyn \& Jacobs, 1984). In response to the moral and legal issues surrounding the living will, the durable power of attorney was proposed. The durable power of attorney allows a patient to designate an agent to make health care decisions on a patient's behalf should the patient become incapacitated. The first Durable Power of Attorney for Health Care Decisions Act was enacted in California in 1984 (Martyn \& Jacobs, 1984).

The early 1990s brought an increased awareness of the aggressive care and unwanted resuscitations that patients were receiving at the EOL (Sabatino, 2010). The out-of-hospital DNR legislations were created to address unwanted medical encounters, particularly resuscitative treatments. Although there are some variations from state to state, the out-of-hospital DNR generally requires a terminally ill patient or a surrogate to request a DNR order from their attending physician. Once the DNR order is completed, the patient receives a DNR necklace or bracelet, which prompts emergency medical services personnel or other healthcare providers to withhold resuscitative measures (Sabatino, 2010).

The complexities of creating and enacting advance directives have driven a trend to simplify state laws. Legislations that combined the living will and durable power of attorney emerged in the early 1990s driven by the public's lack of understanding and the underuse of advance directives (Sabatino, 2010). New Jersey enacted the Advance Directives for Health Care Act in 1991, making it the first state to merge the living will and power of attorney (Sabatino, 2010). 
The proliferation of state legislations consequently resulted in diverse state-tostate statutes that lacked universality, that is, advance directives in one state may not be valid in another. The Uniform Health-Care Decisions Act was approved in 1993 to consolidate state laws and to create a comprehensive yet simplified advance directive (Uniform Law Commission, 1994). To date, only seven states have enacted this legislation (Uniform Law Commission, 2016).

The Patient Self Determination Act, passed in 1990 and federally instituted in 1991, required hospitals, home health agencies, hospice programs and health maintenance organizations to inform patients of their rights to accept or refuse medical care, provide patients with information about advance directives or other legally valid documents, and to ensure that documented medical wishes are implemented (Congressional Research Service, 1990). The Patient Self Determination Act was an educational mandate to inform the public about advance directives.

From the 1990 s to present, the advance directive laws have shifted from a "legal transactional approach" to a "communications approach" (Sabatino, 2010). According to Sabatino (2010), the legal transactional approach is characterized by legal formalities and limitations; however, research evidence reveals that these documents fail to influence EOL care due to a mismatch between specific scenarios in advance directives and the actual scenarios in EOL, and the variability of EOL care preferences over time.

A landmark study on EOL care called the Study to Understand Prognoses and Preferences for Outcomes and Risk of Treatments (SUPPORT) by Connors et al. (1995) aimed to improve EOL decision making and reduce aggressive and prolonged dying process. The multisite study had a total of 9,105 adult hospitalized participants. Phase I 
of the study was a prospective observational study that enrolled 4,301 patients followed by a controlled clinical trial with 4,804 participants. Phase I of the study sought to describe shortcomings in the decision making process and outcomes of seriously ill hospitalized patients. Phase I of the trial revealed a lack of communication among patients and physicians, and revealed the aggressive care that is characteristic EOL experience for most hospitalized patients. In Phase I, $49 \%$ of the 960 patients who indicated the desire to withhold CPR did not have a DNR order. Of the 1,150 patients who died during the study, $79 \%$ had a DNR order but $46 \%$ of orders were written within 2 days of death. Among the phase I decedents, the median number of days spent in the ICU is 8 days, comatose or receiving mechanical ventilation.

Phase II of the study used cluster randomization and assigned 2,152 participants to usual medical care and 2,652 patients to the intervention group (Connors et al., 1995). In response to the shortcomings found on Phase I of the study, the researchers aimed to improve communication and decision making process by providing timely prognostic information to the patients, providing a nurse to facilitate discussions with patients and families, and documentation of patient and family preferences. The results showed no improvement in patient-physician communication. Discussion about CPR occurred in $39 \%$ of the control patients and $41 \%$ of the intervention patients. The number of days spent in the ICU, comatose or receiving mechanical ventilation before death for the intervention and control patients were the same (adjusted ratio for median days, 0.97; 95\% CI). According to the researchers, the lack of improvement in the intervention group may be due to the fact that despite presence of an intervention nurse, physician practice behavior remains unchanged. The researchers also propose that the intervention 
may have positive results if it had occurred in a different setting, earlier in the course of illness and with the physician as an active leader in the discussion rather than a nurse who is not actively involved in the patient care. Early discussions of EOL care preferences with the provider, patient and family members is a central tenet of ACP. This study has been instrumental in directing the national attention on the dire reality of EOL care, and the need to improve the discussion and documentation of patient preference for EOL care.

Fueled by persistent dissatisfaction with EOL care, poor quality of care at the EOL, economic consequence of aggressive futile care, and the failure of legalistic advance directives to guide EOL care, the IOM released a report profiling the state of death and dying in America and made comprehensive recommendations to address EOL care issues (Field \& Cassel, 1997). The IOM report highlighted key recommendations from healthcare systems, policy, and research to the bedside. These recommendations include improving provider education on EOL care, improving palliative care as a medical specialty, increasing number of palliative care providers, and improving patientprovider discussion. The IOM report defines ACP as a more comprehensive rather than a legalistic approach to EOL care discussion by having open discussions with patients, families and providers about prognosis, beliefs and preferences to guide decisions (Field \& Cassel, 1997). The "communications approach" to EOL care discussion lends its fundamental concepts from the IOM definition of ACP (Sabatino, 2010).

Several methods of ACP emerged in the late 1990s including Five Wishes, Caring Conversations and Critical Conditions Planning Guide. These methods have foundational concepts in common, in that these resources meet the legal requirements for 
advance directives, living will and assignment of health care agent or proxy, and includes EOL values and preferences such as comfort and spirituality (Aging with Dignity, 2011; Georgia Health Decisions, 2011).

\section{Physician Orders for Life Sustaining Treatment paradigm}

Physician Orders for Life Sustaining Treatment (POLST) paradigm was created in Oregon in 1991 by health care professionals and medical ethicist in Oregon in response to growing evidence that advance directives failed to direct EOL care and patient's preferences for EOL care were consistently not honored (POLST, n.d.; Schmidt, Zive, Fromme, Cook, \& Tolle, 2014). The POLST is a tool that translates patient's preferences and goals of care into a medical order (POLST, n.d.). The POLST form is intended for patients with serious illness who are likely to die within a year. The POLST process begins with a conversation between the patient and health care provider about values, beliefs, EOL care preferences, and goals of care. The provider then documents the discussed EOL care preferences into a standardized form that is kept in the medical records or with the patient, if the patient lives in the community (Sabatino \& Karp, 2011). The POLST focuses on three key parts: CPR (attempt CPR or DNR), medical interventions (comfort measures only, limited intervention or full treatment), and artificially administered nutrition (Sabatino \& Karp, 2011). As a portable medical order, POLST is honored across all health settings as well as the community. The type of provider authorized to sign the POLST form depends on state regulation, some states allow physicians only, while other states allow physicians, NPs and physician assistants (Sabatino \& Karp, 2011). Nurse practitioners are certified to sign the POLST form or its equivalent in all New England states (POLST, n.d.) 
Research evidence on the consistency between preferences documented on the POLST and actual EOL care received slowly began to emerge in the early 2000s and continues to the present (Hickman et al., 2011; Lee, Brummel-Smith, Meyer, Drew, \& London, 2000). The National POLST Paradigm Task Force (NPPTF) was formed in 2004 to examine and endorse programs that promoted the core elements of POLST (POLST, n.d.). Today, 44 states have a POLST program that has been either fully endorsed by the NPPTF or is in development (POLST, 2016). Respective state POLST programs vary in name. Depending on the state or region, POLST is also referred as Medical Orders for Life Sustaining Treatment (MOLST), Medical Orders for Scope of Treatment (MOST), Clinical Orders for Life Sustaining Treatment (COLST), Life with Dignity Order (LWDO) and Physician Orders for Scope of Treatment (POST) (Sabatino \& Karp, 2011).

\section{Advance Care Planning in New Hampshire}

The first living will statute in New Hampshire (NH) passed in 1985 and the Durable Power of Attorney passed in 1991 (LaFrance \& Leaver, 2007). The Foundation for Healthy Communities (FHC) is a non-profit organization whose mission is to improve health and health care in NH (FHC Mission Statement, n.d.). The FHC initiated townhall-style meetings in 1999 to improve public awareness and accessibility of advance directives (LaFrance \& Leaver, 2007). The FHC found that the public consistently cited concerns about the confusing language and information on the statutory forms for the living will and the Durable Power of Attorney for Healthcare (DPOAH). In response to these concerns, the FHC partnered with the New Hampshire Partnership for End-of-Life Care and developed the "ACP Guide" in 2001 (LaFrance \& Leaver, 2007). The ACP 
guide includes a living will and DPOAH that has been reworded in a consumer friendly language (FHC, 2014). The ACP Guide has been widely used in numerous facilities and offices in NH (LaFrance \& Leaver, 2007). In an annual chart audit by the FHC on the prevalence of advance directives in 26 acute care hospitals in $\mathrm{NH}$, there has been an increase in advance directives reported upon admission from 2011 and 2015 (37\% vs. 49\%) (S. LaFrance, personal communication, July 18, 2016).

The FHC and the New Hampshire Healthcare Decisions Coalition initially launched a POLST program in 2004. However, the results from the pilot program shows that legislation that recognizes portable medical orders needs to be in place before POLST can be successfully implemented (FHC, n.d.). The RSA 137-J was passed in 2006, a statute that includes recognition of the portable DNR (New Hampshire General Court, n.d.). The FHC also developed a portable DNR form that has been used statewide (LaFrance \& Leaver, 2007).

In 2011, the NH Healthcare Decisions Coalition developed a new POLST implementation strategy, which is to make POLST a voluntary standard of care built on the premise of portable medical orders (FHC, n.d.). The new initiative focuses on volunteer-led POLST training programs across the state using the Respecting ChoicesLast Steps Advance Care Planning program. The FHC is the primary source of POLST forms in NH and 10,500 POLST forms has been distributed in in 2015 (S. LaFrance, personal communication, July, 18, 2016). In NH, a POLST form must be signed by a physician or an NP to validate the medical order (FHC, n.d.). According to Shawn LaFrance, executive director of FHC, POLST in NH is 'in development' (S. LaFrance, personal communication, July, 18, 2016). 


\section{Advance Care Planning and the Provider}

Advance care planning guidelines. The IOM released a consensus report titled Dying in America (2014) to improve quality of EOL care and to ensure a sustainable health care system. The IOM recommendations include development of an integrated, patient-centered and family-oriented EOL care, ACP, improvement of professional education on EOL care for all clinicians, payment systems that support quality EOL care, and public education and engagement on EOL care planning (IOM, 2014).

The IOM report emphasizes the critical role of ACP on quality EOL care by ensuring that patient's preferences and needs are met. Furthermore, the report states that $\mathrm{ACP}$ can begin at any age and recommends an open and continuous communication between providers, patients, including seriously ill children and adolescents, and their families. Engaging patients and their families in EOL care discussion promotes shared decision-making and clarification of goals and wishes. The IOM also urged professional organizations to develop standards for ACP discussion and documentation to improve access to ACP documents and compliance with patient's wishes (IOM, 2014).

The IOM, Agency for Healthcare Research and Quality (AHRQ), and the National Guideline Clearinghouse have published guidelines and recommendations for ACP. Advance care planning is recommended at various stages of health: from healthy as part of routine care, specific situations such as persons with genetic disease or those involved in high-risk activities, initial diagnosis of chronic illness, as health worsens or in life threatening illness or event, and to the final year or months of expected life or the frail elderly (AHRQ, 2014; IOM, 2014). Routine or annual review of an advance care 
plan is also recommended as individual preferences may vary over time (AHRQ, 2014;

IOM, 2014; National Guideline Clearinghouse, 2014).

\section{Bioethical principles}

Advance care planning has its foundations based on the bioethical principles of autonomy, beneficence, and non-maleficence. Autonomy is the predominant principle underpinning ACP (IOM, 2014). Autonomy is the decisional capacity to determine what will be done with and to their own person (ANA, 2015). According to ANA code of ethics, the principle of autonomy entitles the patient to be given accurate and complete information to be able to make an informed decision. Autonomy or the right to selfdetermination gives the patient the authority to accept, refuse or terminate treatment. Conversations about patient values and EOL care preferences uphold the patient's right to self-determination and also foster implementation of care that is consistent with the patient's values and preferences.

Beneficence is principle to act for the benefit of others (ANA, 2015). The ANA code of ethics emphasize that the patient's interest must always be the primary commitment of the nurse or NP (ANA, 2015). Non-maleficence is the moral obligation not to inflict harm (ANA, 2015). The President's Council on Bioethics (2005) stated that advance directives offer patients protection against under-treatment or overtreatment thus, promoting the principles of both beneficence and non-maleficence.

\section{Nurse Practitioner scope of practice.}

Several nursing organizations have endorsed ACP as an integral part of patientcentered care. Patient-centered care is achieved through shared decision-making between patient and provider. Nurse practitioners in the primary and acute care settings are 
expected to provide care throughout a care continuum, from care of chronic illness to stabilization of acute conditions to restoration of health to provision of palliative, supportive and EOL care (American Association of Critical-Care Nurses, 2012; American Association of Colleges of Nursing, 2010). The American Association of Critical-Care Nurses (2012) further stressed that the dominant focus of care in NP practice must be to care for the needs of the patient and families especially at the EOL, with an emphasis on the "assurance of a peaceful death".

Open communication between patient and provider regarding ACP is consistent with the nurses' code of ethics. According to the International Council of Nurses Code of Ethics (2012), a nurse or NP must provide accurate, sufficient and timely information to base consent of treatment and individual values and beliefs must be respected. The American Nurses Association (ANA) code of ethics for nurses with interpretative statements iterates the nurses' commitment to the patient and their families as an advocate, and the responsibility to uphold the patients' autonomy (ANA, 2015). Advance care planning discussions ensure that patient's autonomy is upheld by providing patient with adequate information to make informed decisions about preferences for EOL care.

\section{Advance care planning in the curriculum}

In the IOM report, Dying in America, educational institutions and credentialing bodies were urged to strengthen the knowledge and skills of all clinicians in the area of palliative care (IOM, 2014). According to Wheeler (2016), primary palliative care skills are basic yet imperative for all NPs in order to provide holistic and quality care. Primary 
palliative care includes assessment and symptom management, initiating and guiding patients through ACP, and completing advance directives.

Research evidence has shown that lack of education for physicians and NPs is a major barrier in EOL care discussion (De Vleminck et al., 2013; Dube, McCarron, \& Nannini, 2015; Hagen et al., 2015). Although further certification in hospice and palliative care is available for NPs after graduation through the Hospice and Palliative Nursing Association (Hospice and Palliative Credentialing Center, n.d.), studies on palliative care education in the curriculum of graduate nursing programs are limited.

The End-of-Life Nursing Education (ELNEC) graduate project was initiated in 1999 to improve knowledge and education related to EOL care (Malloy, Paice, Virani, \& Ferrell, 2008). The ELNEC-graduate project provided education and training to graduate nursing faculty. The modules include palliative care in advance practice nursing, pain management, symptom management, communications, ethical issues in advanced practice nursing, final hours of life, loss, grief and bereavement, and achieving quality care at the EOL. A follow-up evaluation after the initial ELNEC-graduate project has shown an improvement in palliative care content in the curriculum as well as an increase in the number of hours spent on EOL content in the curriculum (Malloy et al., 2008). However, this student researcher has not found any studies on the short-or long- term effect of ELNEC-graduate program on graduate students.

\section{Reimbursement}

Efforts to reimburse ACP discussion emerged in 2009 under the Patient Protection and Affordable Care Act (PPACA) but opposition and misconceptions amassed which resulted in its deletion of the final version (Giovanni, 2012). In October 
2015, the Centers for Medicare and Medicaid Services (CMS) approved two billing codes to reimburse physicians and non-physician practitioners including NPs to discuss ACP (CMS, 2016). The changes were enacted on January 1, 2016 and stipulate an average of $\$ 86$ reimbursement for the first 30 minutes of ACP discussion in a physician's office or an average of $\$ 80$ in a hospital setting. Medicare will also pay an average of $\$ 75$ for an additional 30 minutes of ACP in both hospital, office and community based settings. (CMS, 2016; Zeitoun, 2015). Furthermore, the new billing schedule allows for ACP discussions to take place at various stages of health regardless of diagnosis (CMS, 2016).

\section{Provider Perspectives on Advance Care Planning}

Inconsistent participation in ACP has prompted numerous studies on providerrelated barriers to ACP. The barriers in these studies can be categorized as provider characteristics, perceived patient characteristics and system characteristics (De Vleminck et al., 2013; Hagen et al., 2015). Hagen et al. (2015) conducted a survey of clinical and administrative health care leaders to elucidate system-specific barriers of ACP and Goals of Care Designation (GCD). Goals of Care Designation is a medical order that is used throughout the Alberta Health Services (2014), and utilizes a coding system to communicate medical care intentions, interventions and locations of care. Fifty-one respondents had backgrounds that included administrators, physicians, nurses and members of the public. According to the authors, the most commonly reported healthcare provider barriers that affect ACP discussions are: the health care provider's mastery of GCD, ineffective staff education programs (51\%) and emotional discomfort in initiating ACP conversations (49\%). System barriers include: insufficient infrastructure to support implementation (82\%), and ineffective public awareness campaign (73\%). 
Resource barriers include: inadequate time for ACP and GCD conversation (78\%) and the need for electronic medical record capability to track GCD orders and ACP conversations (69\%). Patient or public barriers include: insufficient public engagement (84\%) and misunderstanding of ACP (80\%).

De Vleminck et al. (2013) conducted a systematic review to identify barriers and facilitators to ACP discussions from the perspective of general practitioners (GP). Fifteen studies were included; 8 qualitative and 7 cross sectional studies. The researchers found that the most common GP characteristics that pose as barriers to ACP were: lack of knowledge about ACP; perceived lack of skill in ACP discussion and prognostication; emotional discomfort in initiation discussion; and GP attitudes such as perception that patient should initiate the discussion and that other healthcare professionals are better positioned to initiate ACP discussions. The most common patient characteristics that posed as barriers to ACP according to GPs were: patient's perception such as denial of terminal illness and possible misunderstanding or misinterpretation of the GP; anticipated adverse outcomes from ACP discussions such as fear of depriving patient of hope or harming the patient-GP relationship; and incapacity of the patient to make decisions due to dementia or diminished consciousness. Health care system barriers perceived by GPs included: time limitations, and limited resources to honor patients' or families' expectations.

According to De Vleminck, et al. (2013), GP characteristics that facilitated ACP included: younger age; perception of good knowledge and skill in initiating ACP discussions; positive experience with EOL conversations in the past; having their own living will; attitudes which include considering ACP as part of the job; and perception of 
its usefulness. Patient characteristics that were perceived by GPs as facilitators to ACP were: patient's acceptance of terminal illness; patient's knowledge about ACP; and medical condition such as cancer diagnosis or patients with short-term prognosis. Health care system characteristics that were perceived as facilitators to ACP were: long-term patient-GP relationship; multiple contacts with the patient; possibility to devote time; reimbursement; and care setting, GPs report that the home setting is preferred for ACP discussions.

Although studies on NP perceptions on the barriers to ACP is limited, NP responses bear some similarities to studies that focused on physicians. Dube et al. (2015) conducted a quantitative nonexperimental study using the database of a statewide NP organization in Massachusetts. The purpose of the study was to assess prevalence of ACP in NP practice, and to identify barriers and facilitators to ACP. The researchers revealed that $65 \%$ of NPs report having ACP discussions. Nurse practitioners voiced the following responses as barriers to ACP: lack of time, staff shortage, length and type of appointment. System barriers identified were: lack of education, lack of standardized forms, lack of electronic medical record to support documentation and retrieval of information, and lack of leadership support. Factors that were associated with a higher frequency of NP-led ACP discussions were: adequate time and staff, type of appointment, age greater than thirty, practicing in primary care, certification in adult/gerontology, and working in long-term care or inpatient setting. The results reflect the need for extended time for appointments for ACP discussion to comprehensively discuss patients' values and preferences, and to discuss sensitive matters such as prognosis and EOL. Longstanding patient and provider relationship was reported as a facilitator of ACP in 
both physician and NP studies, supporting the notion that ACP should be a process, not a one-time discussion (Dube et al., 2015).

A descriptive, cross-sectional study by Zhou, Stoltzfus, Houldin, Parks and Swan (2010) sought to describe the knowledge, attitudes, practice behaviors and perceived barriers to ACP for oncology advance practice nurses (APRNs). A web-based survey was sent out to one of the author's professional networks and the Oncology Nursing Society's contacts in the Eastern US. The study had 89 respondents. The researchers revealed the following themes on the barriers of ACP as perceived by Oncology APRNs in the order of how frequently the theme was reported: perception of patient or family characteristics such as patient/family denial or reluctance or patient/family friction; physician characteristics such as physician reluctance, or physicians offering another treatment option and delaying ACP discussion; staff discomfort level; and time constraints. This study sheds light on the effect of physician practices to NP practice. The authors theorize that oncologists have higher medical decision-making authority in this specialty, and their reluctance to offer or discuss ACP impedes NPs from initiating ACP discussions. Interestingly, the study also reports that there was a low level of awareness regarding POLST among oncology NPs (Zhou et al., 2010). 


\section{Theoretical Framework}

Although there is substantial evidence that supports the incorporation of ACP into routine patient care, ACP occurs infrequently in practice. Respecting Choices, an evidence-based model for ACP has been integrated in several healthcare organizations in the United States, Canada, Australia, Germany, Spain and Singapore (Detering et al., 2010). However, uptake of ACP in other healthcare organizations and in individual practice has been limited (Lund et al., 2015). Improving practice of ACP requires inquiry into the personal, professional and healthcare system factors that influence behavior of health care professionals.

Numerous theories of behavior change exist but there are none that comprehensively explicate the complex individual and organizational factors that influence behavior change of health care providers. In the past, researchers either used a theory that does not completely explain the theoretical constructs in a study or used multiple theories with overlapping theoretical constructs (Michie et al., 2005). The lack of a solid theoretical basis for implementation of interventions has resulted in mixed responses in the uptake of new guidelines (Michie et al., 2005). According to the authors, behavior change models used in research studies have been mostly educational and lacked a basic understanding of procedures and processes that produce tangible changes in behavior. Cane, O'Connor, \& Michie (2012) assert that although most research literature cites theory, it is often poorly integrated into the development of the study.

The Theoretical Domains Framework (TDF) was developed to aid in strategy development and implementation of evidence-based practice that is applicable to an interdisciplinary audience. Another goal of the TDF was to explore problems with 
implementation and uptake of evidence-based practice among healthcare providers. The TDF is an integrated theory of behavior change that was developed by an expert panel comprised of health psychology theorists, health services researchers and health psychologists (Michie et al., 2005).

The expert panel underwent an exhaustive process of critique, evaluation and validation of theoretical constructs that were grounded in psychological theories that were relevant to behavior change. The panel reached a consensus and identified 12 theoretical domains: knowledge; skills; social/professional role and identity; beliefs about capabilities; beliefs about consequences; motivation and goals; memory, attention and decision process; environmental context and resources; social influences; emotion; behavioral regulation; and nature of the behaviors (Michie et al, 2005).

The TDF has been used in numerous research studies, and in 2012 Cane et al. led a study to further validate the theory and to improve the empirical base of the TDF. The study aimed to examine the content validity of the framework - domain structure, domain content and domain labels. As a result, the framework has been refined to include 14 domains and 84 constructs. The theoretical domains are as follows: knowledge; skills; social/professional role and identity; beliefs about capabilities; optimism; beliefs about consequences; reinforcement; intentions; goals; memory, attention and decision processes; environmental context and resources; social influences; emotions; and behavioral regulation (Cane et al., 2012). The theoretical domains and theoretical constructs under each domain are listed in Appendix A.

According to Cane et al. (2012), the theoretical domain of knowledge is defined as "an awareness of the existence of something" (p. 13). The second theoretical domain 
is skill, defined as an ability or proficiency that one acquires through practice. The third domain is social/ professional role and identity, which is defined as "a coherent set of behavior displayed personal qualities of an individual in a social or work setting" (p. 13).

Beliefs about capabilities is the fourth domain, defined as the acceptance of the truth or validity about an ability, talent or facility that a person can use constructively. The fifth theoretical domain is optimism which the theorists define as "the confidence that things will happen for the best or that desired goals will be attained" (p. 13). A belief about consequences, the sixth theoretical domain, is defined as the acceptance of the truth or the validity about the outcome of a behavior. The theoretical domain of reinforcement is defined as "increasing the probability of a response by arranging a dependent relationship, or contingency, between the response and a given stimulus" (Cane et al., 2012, p. 13).

The theoretical domain of intentions is defined as the "conscious decision to perform a behavior or a resolve to act in a certain way" (Cane et al., 2012, p. 14). The domain of goals is defined as the mental depiction of an outcome that one wants to achieve. Memory, attention and decision process domain is defined as "the ability to retain information, focus selectively on aspects of the environment and choose between two or more alternatives" (p. 14). Environmental context and resources domain is defined as "any circumstance of a person's situation or environment that encourages or discourages the development of skills and abilities, independence, social competence, and adaptive behavior" (p. 14). Social influences domain is the "interpersonal processes that can cause individuals to change their thought, feelings, or behaviors" (p. 14). The emotion domain is defined as "a complex reaction pattern, involving experiential, 
behavioral, and psychological elements, by which the individual attempts to deal with a personally significant matter or event" (p. 14). Lastly, the domain behavioral regulation is defined as anything used with a goal of managing or changing objectively observed or measured actions (Cane et al., 2012).

Evaluation and assessment of barriers and facilitators of ACP discussion that encompasses all constructs of the TDF is beyond the scope of this project. This study will focus on specific constructs in the fourteen theoretical domains to explore NP perspectives on personal, professional and systems-related barriers and facilitators of ACP.

The Advance Care Planning Survey will assess the following domains and their respective constructs: knowledge; skills: competence, ability, skill assessment; professional identity: professional role, group identity, professional boundaries, professional confidence; optimism and pessimism; beliefs about capabilities, beliefs, reinforcement: incentive, consequents, punishment/sanctions; intentions; goals; memory, attention and decision processes: cognitive overload or tiredness; environmental context and resources: stressors, time, organizational culture, barriers and facilitators, presence of an EMR, perception of EMR; social influences: social pressure and norms, group norms, social support; and emotions: fear, anxiety, stress, burn-out, affect (Cane et al., 2012). 


\section{Method}

\section{Purpose}

The purpose of this study was to explore the perspectives of NPs on the barriers and facilitators of ACP.

\section{Research question}

What are the perspectives of NPs on the barriers and facilitators of ACP?

\section{Design}

This study utilized a descriptive survey design using quantitative and qualitative questions.

\section{Sample}

The sample included a nonprobability sample of NPs from the email database of the NHNPA, a statewide advanced practice nurses organization. The NHNPA has 420 active members that includes NPs, NP students and certified nurse anesthetists (CRNA). Of the 420 NHNPA members, 30 members are NP students. The total eligible sample population was therefore 390. The NHNPA was unable to break down the number of NPs and CRNAs. A sample size of 97 NPs (25\%) was projected for the study. Criteria for inclusion were NPs in active practice and were active members of NHNPA during the time of the study. Exclusion criteria included NPs who were inactive members of NHNPA, CRNAs and NP students. Inactive members of the NHNPA were excluded from this study as an inactive status in the organization suggested that the contact information is no longer valid or that the former member does not prefer to participate in activities related to the organization. Certified nurse anesthetists and student NPs do not initiate ACP discussions and were therefore excluded from this study.

\section{Site}


The study was conducted online using the ACP survey on Google forms, a web based survey server.

\section{Procedure}

The NHNPA does not have an Institutional Review Board (IRB). A formal letter of permission to conduct the survey was obtained from Mary Bidgood-Wilson, executive director of NHNPA (Appendix B). An IRB approval was sought and obtained from Rhode Island College (RIC). Once approval from the IRB was obtained, a recruitment email stating an overview of the study (Appendix C), and an informational letter/consent document (Appendix D) with a link to the ACP survey was sent to NHNPA. Settings on Google forms were set to allow only one response from each email address and to unlink responses with the participant's email. The NHNPA then distributed the recruitment email letter, and consent document with the link to the survey to the email addresses on the NHNPA database for its members to complete. A follow-up email was sent 9 days later.

De-indentified responses of the survey were automatically entered in Google spreadsheet. Individual responses were evaluated for completion of the entire survey instrument. Survey results were stored in Google Drive, a cloud-based file storage service that could only be accessed through a password that this student researcher had sole possession of.

\section{Measurement}

The Advance Care Planning Survey by Dube et al. (2015) (Appendix E) was used for this study. Permission to use the ACP survey was obtained from the primary researcher, Monica Dube DNP, FNP-BC. The ACP questionnaire has 36 questions 
distributed in 5 sections that include: demographic data, professional data, personal data, practice data and the End of Life Care Decisions Questionnaire (EOLCDQ II). In order to succinctly capture the answer to the research question and to potentially increase participation, the survey instrument used for this study excluded the personal data and EOLCDQ II sections. This study utilized the demographic, professional and practice data sections of the ACP survey. Questions in the demographic and professional data sections that were deemed irrelevant to the purpose of this study, such as race and the region where the respondent practiced, were omitted. A question on whether the respondent practices primary care was also omitted because a question on area of practice is already in place.

Practice data questions listed the most common barriers and facilitators of ACP found in literature. The participants were asked to rate the extent to which each item was perceived as a barrier or facilitator to ACP. The Likert scale ranged from 0 to 5 , with $0=$ not likely a barrier or facilitator and $5=$ most likely a barrier or facilitator. An option labeled as 'other' at the end of the list of barriers and facilitators was available for participants to identify a barrier or facilitator encountered in their practice that was not on the list. Open-ended questions found at the end of both the barrier and facilitator sections aimed to explore participants' comments and other thoughts on ACP.

The survey instrument was displayed on Google forms with one section of the survey per page. The online ACP survey instrument was pilot tested on 3 NP students to evaluate content, readability and comprehensibility, and to evaluate congruence of information entered by NP students and results shown on Google forms and Google spreadsheet. The students who participated on the pilot survey reported that the survey 
was easy to comprehend and complete, and indicated that there were no changes necessary.

\section{Data Analysis}

Responses were automatically entered to Google spreadsheet. Results are displayed in tables. Descriptive statistics were utilized to describe respondents' demographic and professional characteristics. Likert scale responses were calculated to obtain statistical means and standard deviations. The open-ended responses were analyzed for repetition of concepts or recurring ideas to identify common themes. Findings from a study by Dube et al. (2015) that used the same ACP survey were examined to compare results. 


\section{Results}

\section{Sample}

A total of 67 survey responses were received. Two respondents reported a Bachelor's degree as their highest educational attainment. Nurse Practitioners are required to have a graduate or post-graduate degree to obtain certification as an NP. Therefore, the 2 respondents who indicated that their highest educational attainment was a Bachelor's degree were excluded from the total sample, as their educational background implied that the respondents were not certified NPs. A total of 65 (16.6\%) out of the 390 eligible members of the NHNPA completed the survey and were included in the sample.

Demographic information is illustrated in Table 1. Sixty-three (96.9\%) of the respondents were female. The highest number of respondents $(36.9 \%)$ belonged to the 50-59 age group, followed by the 40-49 age group (23.1\%) and the 60-65 age group $(21.5 \%)$. Majority of the respondents $(83.1 \%)$ reported that their highest level of nursing education is a master's degree, followed by a Doctorate in Nursing Practice (DNP) (12.3\%) and Doctor of Philosophy (PhD)/Doctor of Education (EdD) (4.6\%).

\section{Table 1}

Demographic Information

\begin{tabular}{|l|l|l|}
\hline \multicolumn{1}{|c|}{ Characteristics } & \multicolumn{1}{|c|}{ Number of Participants } & Percentage \\
\hline Age & $\mathrm{n}=65$ & \\
$20-29$ & 1 & $1.5 \%$ \\
$30-39$ & 8 & $12.3 \%$ \\
\hline
\end{tabular}




\begin{tabular}{|l|l|l|}
\hline $40-49$ & 15 & $23.1 \%$ \\
$50-59$ & 24 & $36.9 \%$ \\
$60-65$ & 14 & $21.5 \%$ \\
Greater than 65 & 3 & $4.6 \%$ \\
\hline $\begin{array}{l}\text { Gender } \\
\text { Male }\end{array}$ & $\mathrm{n}=65$ & $3.1 \%$ \\
Female & 2 & $96.9 \%$ \\
\hline Highest Level of Education & $\mathrm{n}=65$ & $83.1 \%$ \\
Master's Degree & 54 & $4.6 \%$ \\
PhD/EdD & 3 & $12.3 \%$ \\
DNP & 8 & \\
\hline
\end{tabular}

Professional data results revealed that $40 \%$ (26) of the participants worked greater than 40 hours per week and another $40 \%$ worked 31-40 hours per week. Practice setting varied among participants: $31.3 \%$ (20) worked in a physician's office or communitybased outpatient setting, 23.4\% (15) worked in a hospital outpatient setting, 10.9\% (7) worked in the hospital inpatient setting, $7.8 \%$ (5) worked in the community setting, $6.3 \%$ (4) worked in the nursing home or other long term care facility, and 20.3\% (13) worked in other practice settings. Participants who indicated their work setting as 'other' have listed independent practice, addiction/detox center, corrections facility, college health, and occupational health as their work settings. Majority of the respondents $47.7 \%$ indicated that they are certified as Family NPs, while $20 \%$ had certification in Adult/Gerontology.

Sixty-four participants responded to the question on years of practice as an NP. Of the 64 respondents, $37.5 \%$ had 16-25 years of practice as an NP followed by 0-5 years 
of practice (26.6\%), 6-15 years of practice (20.3\%), and greater than 25 years of practice (15.6\%). Of the 65 respondents, $47.7 \%$ had formal EOL care covered in their NP education. Thirty-eight respondents $(58.5 \%)$ indicate that they have taken continuing education course on EOL care issues. Forty-two respondents (64.6\%) were aware of the federal mandate to provide ACP discussions to patients.

Table 2

Professional Data

\begin{tabular}{|c|c|c|}
\hline Professional Data Questions & $\begin{array}{l}\text { Number of } \\
\text { Participants }\end{array}$ & Percentage \\
\hline Hours of Practice Weekly & $\mathrm{n}=65$ & \\
\hline Less than 20 hours & 10 & $15.4 \%$ \\
\hline 21-30 hours & 3 & $4.6 \%$ \\
\hline 31-40 hours & 26 & $40 \%$ \\
\hline Greater than 40 hours & 26 & $40 \%$ \\
\hline Practice Setting & $\mathrm{n}=64$ & \\
\hline $\begin{array}{l}\text { Physician office/Community- } \\
\text { based outpatient }\end{array}$ & 20 & $31.3 \%$ \\
\hline Hospital outpatient & 15 & $23.4 \%$ \\
\hline Community & 5 & $7.8 \%$ \\
\hline Hospital Inpatient & 7 & $10.9 \%$ \\
\hline $\begin{array}{l}\text { Nursing home or other long-term } \\
\text { care }\end{array}$ & 4 & \\
\hline Other & 13 & $20.3 \%$ \\
\hline Certification Specialty & $\mathrm{n}=65$ & \\
\hline Family & 31 & $47.7 \%$ \\
\hline Adult/Gerontology & 13 & $20 \%$ \\
\hline
\end{tabular}




\begin{tabular}{|c|l|l|}
\hline Pediatric & 2 & $3.1 \%$ \\
Women's Health & 1 & $1.5 \%$ \\
Other & 2 & $3.1 \%$ \\
\hline Number of Years in Practice as NP & 16 & $24.6 \%$ \\
$0-5$ & 17 & \\
$6-15$ & 13 & $26.6 \%$ \\
$16-25$ & 24 & $20.3 \%$ \\
Greater than 25 years & 10 & $37.5 \%$ \\
\hline $\begin{array}{l}\text { Was End-of-Life care covered in } \\
\text { your formal NP education? }\end{array}$ & $\mathrm{n}=65$ & $15.6 \%$ \\
$\begin{array}{l}\text { Yes } \\
\text { No }\end{array}$ & 31 & $47.7 \%$ \\
\hline $\begin{array}{l}\text { Have you ever taken a continuing } \\
\text { education course or seminar in } \\
\text { End-of-Life care issues? }\end{array}$ & $\mathrm{n}=65$ & $52.3 \%$ \\
$\begin{array}{c}\text { Yes } \\
\text { No }\end{array}$ & 38 & $54.6 \%$ \\
\hline $\begin{array}{l}\text { Are you aware of the federal } \\
\text { mandate to provide Advance Care } \\
\text { Planning discussions to patients? }\end{array}$ & $\mathrm{n}=65$ & $35.4 \%$ \\
$\begin{array}{l}\text { Yes } \\
\text { No }\end{array}$ & 42 & \\
\hline
\end{tabular}

Practice data questions asked participants to rate items on a list of barriers and facilitators to ACP using a Likert scale according to the extent that they have posed as a barrier or facilitator to ACP. Barrier and facilitators of ACP were analyzed by calculating the statistical mean (M) and standard deviation (SD). A complete list of the barriers to ACP and responses are described in Table 3. The most common barriers were 
type of appointment $(M=2.96 ; \mathrm{SD}=1.71)$, lack of time $(\mathrm{M}=2.79 ; \mathrm{SD}=1.71)$, and length of appointment $(\mathrm{M}=2.53 ; \mathrm{SD}=1.74)$. Standard deviations to all the answers on the barriers question ranged from 1.23 to 1.83 . The barrier that was least reported by participants were lack of electronic medical record $(\mathrm{M}=0.59)$, discomfort with the topic $(M=0.75)$, and concern about upsetting the patient $(M=1.15)$.

Table 3

Practice Data: Barriers to Advance Care Planning

\begin{tabular}{|c|c|c|c|}
\hline $\begin{array}{c}\text { Barriers to Advance } \\
\text { Care Planning }\end{array}$ & $\mathrm{n}$ & Mean & $\begin{array}{l}\text { Standard } \\
\text { Deviation }\end{array}$ \\
\hline Lack of Time & 64 & 2.79 & 1.83 \\
\hline Staff Shortage & 65 & 1.73 & 1.62 \\
\hline Length of Appointment & 65 & 2.53 & 1.74 \\
\hline Type of Appointment & 64 & 2.96 & 1.71 \\
\hline $\begin{array}{l}\text { Lack of Education/ } \\
\text { Training }\end{array}$ & 64 & 1.64 & 1.69 \\
\hline $\begin{array}{l}\text { Lack of Available } \\
\text { Forms }\end{array}$ & 64 & 1.93 & 1.89 \\
\hline $\begin{array}{l}\text { Lack of Electronic } \\
\text { Medical Record }\end{array}$ & 64 & 0.59 & 1.23 \\
\hline $\begin{array}{l}\text { Lack of Leadership } \\
\text { Support }\end{array}$ & 65 & 1.23 & 1.52 \\
\hline $\begin{array}{l}\text { Discomfort with the } \\
\text { Topic }\end{array}$ & 64 & 0.75 & 1.35 \\
\hline
\end{tabular}




\begin{tabular}{|l|l|l|l|}
\hline $\begin{array}{l}\text { Concern about Upsetting } \\
\text { the Patient }\end{array}$ & 64 & 1.15 & 1.32 \\
\hline
\end{tabular}

An open-ended question on the barriers that participants encountered in their practice and their thoughts on ACP elicited major themes (Table 4). These themes include time constraints, perception that ACP is not appropriate in their practice setting, perception of inappropriateness of ACP discussions during the acute phase of illness, patient readiness, and religious or cultural barriers.

\section{Table 4}

Other barriers:

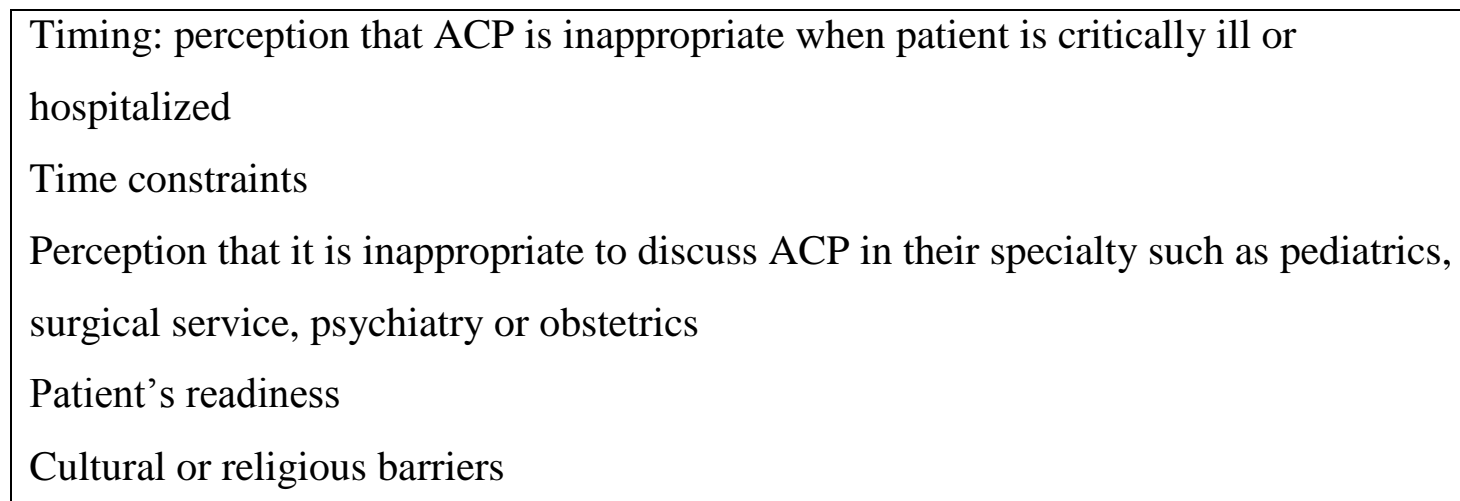

The full list of the facilitators of ACP and the responses are illustrated in Table 5. The most common facilitators of ACP were personal experience $(\mathrm{M}=3.86$; $\mathrm{SD}=1.47)$, comfort with the topic $(\mathrm{M}=3.81 ; \mathrm{SD}=1.60)$, long-term relationship with the patient ( $\mathrm{M}$ $=3.76 ; \mathrm{SD}=1.84)$ and previous education and training $(\mathrm{M}=3.58 ; \mathrm{SD}=1.71)$. Standard deviations on the facilitator question ranged from 1.47 to 1.99 . The items rated as least likely to be a facilitator of $\mathrm{ACP}$ were: having electronic medical record $(\mathrm{M}=1.84 ; \mathrm{SD}=$ $1.99)$ and adequate staff $(\mathrm{M}=2.86 ; \mathrm{SD}=1.63)$. 
Table 5

Practice Data: Facilitators of Advance Care Planning

\begin{tabular}{|c|c|c|c|}
\hline $\begin{array}{c}\text { Facilitators of Advance } \\
\text { Care Planning }\end{array}$ & $\mathrm{n}$ & Mean & $\begin{array}{l}\text { Standard } \\
\text { Deviation }\end{array}$ \\
\hline Length of Appointment & 65 & 3.30 & 1.72 \\
\hline Adequate staff & 65 & 2.86 & 1.63 \\
\hline Type of Appointment & 65 & 3.23 & 1.70 \\
\hline $\begin{array}{l}\text { Having Electronic Medical } \\
\text { Record }\end{array}$ & 65 & 1.84 & 1.99 \\
\hline Availability of Forms & 63 & 3.12 & 1.97 \\
\hline Support of Leadership & 63 & 3.01 & 1.92 \\
\hline $\begin{array}{l}\text { Long term Relationship } \\
\text { with the Patient }\end{array}$ & 64 & 3.76 & 1.84 \\
\hline Understanding the Forms & 65 & 3.36 & 1.84 \\
\hline Comfort with the Topic & 64 & 3.81 & 1.60 \\
\hline $\begin{array}{l}\text { Previous } \\
\text { Education/Training }\end{array}$ & 65 & 3.58 & 1.71 \\
\hline Personal Experience & 65 & 3.86 & 1.47 \\
\hline
\end{tabular}

An open-ended question on other facilitators of ACP (Table 6) and other thoughts on ACP (Table 7) raised some major themes that participants perceived as facilitators of ACP. These themes include availability of a designated employee to facilitate ACP 
discussions, longer time with patient, availability of ACP documents in different languages or availability of a translator, presence of significant caregivers or family at the appointment, and presence of an interdisciplinary team to address ACP needs.

Table 6

Other facilitators

Having a designated employee available to assist with completion of ACP Availability of forms in different languages and availability of a translator

Table 7

Is there anything else regarding barriers and facilitators in your practice that you think I should know about?

Perception that other specialties are more appropriate and more prepared to discuss ACP

The need for an interdisciplinary team to address patient's and family's needs Perceived inappropriateness of ACP discussions during the acute phase of illness Presence of numerous outcome measures that must be met in each visit precludes ACP discussions 


\section{Summary and Conclusions}

A vast majority of Americans die receiving aggressive care that is inconsistent with their wishes. While most patients report that they want to avoid hospitalizations and aggressive care at the EOL (Dartmouth Atlas of Health Care, 2012), research evidence reveals otherwise. Increase in intensity and aggressiveness of care at the EOL has been well documented (Riley \& Lubitz, 2010). Advance care planning has been shown to increase concordance between patient's wishes and actual care received at EOL, increased quality of life scores, increased utilization of hospice and palliative care resources and better quality of life among the bereaved (Detering et al., 2010; Wright et al., 2008). Despite medical and nursing guidelines, and research evidence that support ACP discussions, these discussions rarely occur (Keary \& Moorman et al., 2015; Macks et al., 2010). Improving and increasing the practice of ACP begins by inquiry into the personal, professional and systems factors that affect the uptake of evidence-based guidelines (Michie et al., 2005). This study explored the perspectives of NPs on the barriers and facilitators that they encounter in initiating ACP discussions.

A web-based ACP survey was sent to the members of the NHNPA, a statewide advanced practice nurses organization. The sample consisted of 65 participants who completed a one-time survey that included questions on demographic, professional data and practice data. The practice data section included a list of barriers and facilitators of ACP for the participants to rate using a Likert scale. The participants were also asked to identify other barriers and facilitators to ACP in their practice via three open ended questions. 
Less than half $(47.7 \%)$ of the participants had formal EOL care covered in their NP education or curriculum. The majority of participants $(58.5 \%)$ reported that they had taken continuing education courses on EOL care issues, indicating an interest among participants in various aspects of EOL care; conversely, this result also indicates a lack of further EOL education on more than $40 \%$ of the respondents. Only $64.6 \%$ of participants were aware of the federal mandate to provide ACP discussions to patients.

The most commonly reported barriers to ACP were related to time. The barriers commonly identified were type of appointment, lack of time, and length of appointment. Lack of available forms was the most common systems related barrier, followed by lack of education and training. The least rated barriers were lack of electronic medical record and discomfort with the topic. The open ended question about other barriers encountered in practice revealed two major themes: the perception that ACP discussions are difficult and inappropriate in acute illness and in certain specialties such as surgery, pediatrics or psychiatry, and patient readiness.

The most common facilitators to ACP were personal experience $(\mathrm{M}=3.68 ; \mathrm{SD}=$ 1.47), comfort with the topic $(M=3.81$; $\mathrm{SD} 1.60)$, and long-term relationship $(\mathrm{M}=3.76$; SD 1.84) with the patient. Previous education and training was also reported as a facilitator by $66.2 \%$ of participants $(\mathrm{M}=3.58$; $\mathrm{SD}=1.47)$. Time-related factors such as length of appointment $(\mathrm{M}=3.30 ; \mathrm{SD} 1.72)$ and type of appointment $(\mathrm{M}=3.23 ; \mathrm{SD}=$ 1.70) were viewed as facilitators to ACP. System factors such as availability of forms and support of leadership were positively viewed as a facilitator. Having electronic medical record was reported as the factor least likely to be a facilitator to ACP. An openended question on other facilitators encountered in practice revealed the following 
themes: having a designated employee to assist in ACP discussions, and availability of forms in different languages or presence of a translator. An open ended question on other thoughts on ACP resulted in themes that supported and revealed more barriers and facilitators. The major themes include: perception that other specialties such as palliative care are more appropriate and are better equipped to discuss ACP, multiplicity of outcome measures required in each visit often supersede ACP discussions, and the need for an interdisciplinary team to address the numerous needs that may arise on ACP discussions.

The results of this study are consistent with evidence found in the literature on the barriers and facilitators to ACP by providers. Inadequate time for ACP discussions has been well documented as a significant barrier to ACP by both NPs and physicians (Dube et al., 2015; Hagen et al., 2015; De Vleminck et al., 2013). The respondents expressed that numerous outcome measures that must be completed during each visit take precedence over ACP discussions.

Systems related barriers such as lack of available forms and lack of education were also reported by Dube et al. (2015), a study from which the ACP survey was adapted. In addition, lack of education and perceived lack of skill by physicians and other healthcare providers were reported as major barriers by Hagen et al. (2015) and De Vleminck et al. (2013). In contrast, personal experience, previous education and training, and comfort with the topic were viewed as significant facilitators to ACP. There is evidence that provider perception of good knowledge and skill in ACP facilitates the practice of ACP (De Vleminck et al., 2013). This research evidence suggests that didactic and experiential learning are essential to develop characteristics that promote 
provider participation in ACP with their patients. Long term studies on EOL care education programs such as the ELNEC project are needed to evaluate the effect of EOL education and training in the quality and frequency of ACP discussions.

The perception of poor patient understanding and lack in patient readiness as barriers to ACP was consistent with other studies (Hagen et al., 2015; De Vleminck et al., 2013; Zhou et al., 2010). Increasing public awareness of the importance and process of ACP is essential to facilitate ACP discussions.

The support of leadership and availability of forms were viewed as facilitators to ACP. Implementation of an evidence-based practice requires support from various stakeholders in the political arena, healthcare system and hospital administration. An interdisciplinary approach is also important to facilitate sustained and successful adaptation of an evidence-based practice. Availability of forms in different languages, presence of a translator, social worker and case managers are few of the essential tools to facilitate a successful ACP discussion.

There are some limitations to this study. These limitations include convenience sampling, a small sample size, and the lack of gender diversity among participants. The majority of the participants in this study were women (96.9\%). Women make up $91 \%$ of the NP population in NH, higher than the national average (87\%) (Kaiser Family Foundation, 2016). A plausible limitation is the lack of racial diversity in NH. According to the 2015 United States Census, 93.9\% of residents in NH are non-Hispanic White (United States Census Bureau, 2015). A study with a largely homogenous sample underrepresents minority groups and other gender identities. A sample from a "thin slice 
of humanity" produces a narrow perspective and limits generalizability (Henrich, Heine, \& Norenzayan, 2010). This study also did not include possible issues with physician practice behavior that may affect NP practice as reported by Zhou et al. (2010).

Overall, time related factors were viewed as a significant barrier to ACP. The participants expressed that $\mathrm{ACP}$ is inappropriate in certain specialties and scenarios. Personal factors such as personal experience, comfort with EOL discussion, and longterm relationship with the patient were the most common facilitators to ACP. These results suggest that a healthcare provider such as the primary care provider who has regular contact with a patient may be better positioned to provide ACP discussions rather than a specialist whose contact with a patient is short and sporadic.

Longer appointments and type of appointment was viewed as facilitators to ACP. Participants reported that systems-related factors such as previous training and education, and availability of forms facilitated ACP. Participants also reported that the presence of an ACP expert or designated employee and interdisciplinary team to address ACP needs, availability of forms in different languages, presence of family members in appointments would facilitate ACP discussions. These results reflect the numerous domains that affect practice in healthcare, encompassing personal, professional and organizational factors (Michie et al., 2005). 


\section{Recommendations and Implications for Advanced Nursing Practice}

The findings of this study have several implications for the nursing profession and more specifically for advance nursing practice. Assisting patients and families with ACP can require the clinical expertise and communication skills of an advanced practice nurse to assess prognosis, consider treatment options, and to help clarify the goals of care of the patient. This study supports improvements in research, education, policy, leadership and professional practice to advance the practice of ACP. Promoting and improving the practice of ACP will require comprehensive changes across the healthcare system and among healthcare providers, as well as more public education regarding ACP and EOL care.

This study highlights the need for more research on the variables that affect ACP discussions. There is a paucity of research in the perspectives of patients on ACP discussions. Providers often cite patient readiness and religious or cultural factors as significant barriers to ACP. Further research is needed to allow providers to objectively assess patient readiness for ACP, and to assist patients and families to develop readiness and improve engagement in ACP discussions. An evidence-based approach to ACP discussion is necessary to promote a conversation that is open, patient-centered, and sensitive to the patient's culture and beliefs.

This study has revealed that previous education and training has been viewed as a major facilitator to ACP discussions. However, lack of education on ACP and EOL care issues has been reflected in numerous studies (De Vleminck et al., 2013; Dube et al., 2015; Hagen et al., 2015). More comprehensive palliative and EOL care content needs to 
be incorporated into undergraduate and graduate curriculums to equip nurses and APRNs with the knowledge and skills to address ACP, especially for patients and families dealing with serious illness and EOL. Ensuring that NPs are equipped with 'primary' palliative care skills is imperative in providing quality, holistic care to patients along the care continuum (Wheeler, 2016). Furthermore, NPs who work in certain patient populations such as oncology or geriatrics must consider pursuing advanced certification in hospice and palliative care. The findings in this study reveal that personal experience has been reported as a facilitator to ACP. Experiential-based learning is essential to the application of theoretical knowledge; therefore, simulation or clinical rotations that expose students to ACP discussion and EOL care may facilitate meaningful learning.

The findings of this study revealed that time related factors are the most significant barrier to ACP discussions. Physicians and NPs have reported the impact of time constraints to the practice of ACP. This research evidence has several implications on healthcare policy and leadership. Advance practice nurses must advocate and lobby for better payment and scheduling systems that promote and facilitate ACP discussions. Although there has been some progress in the reimbursement of ACP discussions, there is no policy that requires its completion on regular or annual visits. Advanced practice nurses should continue to contribute to the evidence base to establish best practices and guidelines for ACP, and to evaluate the impact of ACP on cost, safety and quality. This may help to support ACP as a priority to be incorporated throughout the healthcare system.

The IOM recommends ACP to all patients, and highly supports regular ACP discussions to patients with chronic or terminal illness, or patients with life threatening 
diagnoses, and the elderly (IOM, 2014). Policies must be in place to mandate providers to have ACP discussions with certain patient populations such as patients with chronic, progressive conditions or the terminally ill. Incentivizing the practice of ACP discussions by including ACP as a performance measure of value-based purchasing payment models may further facilitate ACP discussions.

Advance care planning discussions are complex and issues may arise during the discussion that are beyond the scope of the provider. Leaders must ensure that there is support staff available during or after ACP discussion to further assist patients and their families with the needs that arise during the discussion. Inclusion of an interdisciplinary team consisting of social worker, case manager, and translator, if necessary, is recommended to alleviate provider load, provide holistic patient-and family-centered care, and improve overall quality of care.

Improving public awareness of ACP must be prioritized. Respondents in this study reported that patient-related factors such as readiness and beliefs as a barrier to ACP. Hagen et al. (2015) reported that insufficient public engagement and public misunderstanding are major barriers in ACP discussions. According to a survey by the Conversation Project (2013), 90\% of Americans think that they should have conversations about their EOL care but only $30 \%$ have had actual conversations. There is a persistent, widespread lack of understanding of ACP and advance directives. As leaders, APRNs must support and initiate public forums such as The Hospice Foundation of America's Being Mortal project (n.d.). This project is a national awareness campaign to encourage the public to make EOL preferences known. Improving public awareness of 
the current realities of EOL care, and education on the steps to making EOL preferences known is essential to begin the conversation and demystify the ACP process. 


\section{References}

Agency for Healthcare Research and Quality. (2014). Effective health care program technical brief number 16 decision aids for advance care planning. Retrieved from https://effectivehealthcare.ahrq.gov/ehc/products/550/1938/advance-caredecision-aids-report-140729.pdf

Aging with Dignity. (2011). Five wishes. Retrieved from https://agingwithdignity.org/docs/default-source/default-documentlibrary/product-samples/fwsample.pdf?sfvrsn=2

Alberta Health Services. (2014). Advance care planning and goals of care designation. Retrieved from https://extranet.ahsnet.ca/teams/policydocuments/1/clp-advancecare-planning-hcs-38-policy.pdf

American Association of Colleges of Nursing. (2010). Adult-gerontology primary care nurse practitioner competencies. Retrieved from http://www.aacn.nche.edu/geriatric-nursing/adultgeroprimcareNPcomp.pdf

American Association of Critical Care Nurses. (2012). AACN scope and standards for acute care nurse practitioner practice. Retrieved from http://www.aacn.org/wd/practice/docs/acnp-scope-and-standards.pdf

American Nurses Association. (2015). Code of ethics for nurses with interpretative statements. Retrieved from http://nursingworld.org/DocumentVault/Ethics1/Code-of-Ethics-for-Nurses.html

Barnato, A. E., Herndon, M. B., Anthony, D. L., Gallagher, P. M., Skinner, J. S., Bynum, J. P., \& Fisher, E. S. (2007). Are regional variations in end-of-life care intensity explained by patient preferences? A study of the US Medicare population. Medical Care, 45(5), 386-393. 
Billingham, M. J., \& Billingham, S. J. (2013). Congruence between preferred and actual place of death according to the presence of malignant or non-malignant disease: A systematic review and meta-analysis. BMJ Supportive \& Palliative Care, 3(2), 144-154.

Bischoff, K. E., Sudore, R., Miao, Y., Boscardin, W. J., \& Smith, A. K. (2013). Advance care planning and the quality of end-of-life care in older adults. Journal of the American Geriatrics Society, 61(2), 209-214.

Burge, A. T., Lee, A., Nicholes, M., Purcell, S., Miller, B., Norris, N., ... \& Holland, A. E. (2013). Advance care planning education in pulmonary rehabilitation: A qualitative study exploring participant perspectives. Palliative Medicine, 3(6), 508-515.

Cane, J., O’Connor, D., \& Michie, S. (2012). Validation of the theoretical domains framework for use in behaviour change and implementation research. Implementation Science, 7(1), 1-17.

Centers for Disease Control and Prevention. (1906). Mortality statistics 1900-1904. Retrieved from http://www.cdc.gov/nchs/data/vsushistorical/mortstatsh_19001904.pdf

Centers for Disease Control and Prevention. (2010a). Life expectancy at birth, at 65 years of age, and at 75 years of age, by race and sex: United States, selected years 19002007. Retrieved from http://www.cdc.gov/nchs/data/hus/2010/022.pdf

Centers for Disease Control and Prevention. (2010b). Place of death, over time: United States, 1989, 1997, and 2007. Retrieved from http://www.cdc.gov/nchs/data/hus/2010/fig33.pdf 
Centers for Disease Control and Prevention. (2013). Deaths and mortality. Retrieved from http://www.cdc.gov/nchs/fastats/deaths.htm

Centers for Medicare and Medicaid Services. (2016). Frequently asked questions about billing the physician fee schedule for advance care planning services. Retrieved from https://www.cms.gov/Medicare/Medicare-Fee-for-ServicePayment/PhysicianFeeSched/Downloads/FAQ-Advance-Care-Planning.pdf

Center for Practical Bioethics. (2013). Caring Conversations. Retrieved from https://practicalbioethics.org/files/caring-conversations/Caring-Conversations.pdf Congressional Research Service. (1990). H.R.4449 - 101st Congress (1989-1990): Patient Self Determination Act of 1990. Retrieved from https://www.congress.gov/bill/101st-congress/house-bill/4449

Connors, A. F., Dawson, N. V., Desbiens, N. A., Fulkerson, W. J., Goldman, L., Knaus, W. A., ... \& Hakim, R. (1995). A controlled trial to improve care for seriously ill hospitalized patients: The study to understand prognoses and preferences for outcomes and risks of treatments (SUPPORT). The Journal of the American Medical Association, 274(20), 1591-1598.

Colby, S. L., \& Ortman, J. M. (2015). Projections of the size and composition of the US population: 2014 to 2060. US Census Bureau. Retrieved from http://www.census.gov/content/dam/Census/library/publications/2015/demo/p251143.pdf

Dartmouth Atlas of Health Care. (2012). Inpatient days per decedent during the last six months of life, by gender and level of care intensity. Retrieved from http://www.dartmouthatlas.org/data/topic/topic.aspx?cat=18 
Dartmouth Atlas of Health Care (2016). Care of chronic illness in the last two years of life. Retrieved from http://www.dartmouthatlas.org/data/topic/topic.aspx?cat=1

Davison, S. N. (2006). Facilitating advance care planning for patients with end-stage renal disease: The patient perspective. Clinical Journal of the American Society of Nephrology, 1(5), 1023-1028.

Detering, K. M., Hancock, A. D., Reade, M. C., \& Silvester, W. (2010). The impact of advance care planning on end of life care in elderly patients: Randomized controlled trial. British Medical Journal, 340 (7751), 847-855.

De Vleminck, A., Houttekier, D., Pardon, K., Deschepper, R., Van Audenhove, C., Vander Stichele, R., \& Deliens, L. (2013). Barriers and facilitators for general practitioners to engage in advance care planning: A systematic review. Scandinavian Journal of Primary Health Care, 31(4), 215-226.

Ditto, P. H., Jacobson, J. A., Smucker, W. D., Danks, J. H., \& Fagerlin, A. (2006). Context changes choices: A prospective study of the effects of hospitalization on life-sustaining treatment preferences. Medical Decision Making, 26(4), 313-322.

Doll, K. M., Stine, J. E., Van Le, L., Moore, D. T., Bae-Jump, V., Brewster, W. R., ... \& Kim, K. H. (2013). Outpatient end of life discussions shorten hospital admissions in gynecologic oncology patients. Gynecologic Oncology, 130(1), 152-155.

Dube, M., McCarron, A., \& Nannini, A. (2015). Advance care planning complexities for nurse practitioners. The Journal for Nurse Practitioners, 11(8), 766-773.

Field, M. J. \& Cassel, C.K. (1997). Approaching death: Improving care at the end of life. National Academies Press. Retrieved from https://www.nap.edu/read/5801/chapter/1 
Foundation for Healthy Communities. (2014). Advance care planning guide. Retrieved from http://www.healthynh.com/images/PDFfiles/advancedirectives/ACP\%20Guide\%20revised\%20022014.pdf

Foundation for Healthy Communities. (n.d.). Mission statement. Retrieved from http://www.healthynh.com/index.php/about-us/mission-statement.html

Foundation for Healthy Communities. (n.d.). POLST Frequently asked questions for providers. Retrieved from http://www.healthynh.com/images/PDFfiles/advancedirectives/POLST/POLST\%20Frequently\%20Asked\%20Questions\%20for\%20Pr oviders.pdf

Giovanni, L. A. (2012). End-of-life care in the United States: Current reality and future promise-a policy review. Nursing Economics, 30(3), 127

Goodman, D.C., Esty, A.R., Fisher, E.S., \& Chang, C.H. (2011). Trends and variation in end-of-life care for Medicare beneficiaries with severe chronic illness. The Dartmouth Atlas of Health Care. Retrieved from http://www.dartmouthatlas.org/downloads/reports/EOL_Trend_Report_0411.pdf

Georgia Health Decisions. (2011). The critical conditions planning guide. Retrieved from http://georgiahealthdecisions.org/preview.html

Giovanni, L. A. (2012). End-of-life care in the United States: Current reality and future promise-A policy review. Nursing Economics, 30(3), 127-134.

Glick, H.R. \& Hays, S.P. (1991). Innovation and reinvention in state policymaking: Theory and the evolution of living will laws. The Journal of Politics, 53(3), 835850. 
Hagen, N. A., Howlett, J., Sharma, N. C., Biondo, P., Holroyd-Leduc, J., Fassbender, K., \& Simon, J. (2015). Advance care planning: Identifying system-specific barriers and facilitators. Current Oncology, 22(4), e237-e245.

Henrich, J., Heine, S. J., \& Norenzayan, A. (2010). The weirdest people in the world?. Behavioral and Brain Sciences, 33(2-3), 61-83.

Heyland, D. K., Barwich, D., Pichora, D., Dodek, P., Lamontagne, F., You, J. J., ... \& ACCEPT (Advance Care Planning Evaluation in Elderly Patients) Study Team. (2013). Failure to engage hospitalized elderly patients and their families in advance care planning. JAMA Internal Medicine, 173(9), 778-787.

Hickman, S. E., Nelson, C. A., Moss, A. H., Tolle, S. W., Perrin, N. A., \& Hammes, B. J. (2011). The consistency between treatments provided to nursing facility residents and orders on the physician orders for life- sustaining treatment form. Journal of the American Geriatrics Society, 59(11), 2091-2099.

Hospice and Palliative Credentialing Center. (n.d.). Advanced certified hospice and palliative care nurse. Retrieved from http://hpcc.advancingexpertcare.org/competence/aprn-achpn/

International Council of Nurses. (2012). The ICN code of ethics for nurses. Retrieved from http://www.icn.ch/images/stories/documents/about/icncode_english.pdf Institute of Medicine of the National Academies. (2014). Dying in America: Improving quality and honoring individual preferences near the end of life. Retrieved from http://www.nap.edu/read/18748/chapter/5 
Keary, S., \& Moorman, S. M. (2015). Patient-physician end-of-life discussions in the routine care of Medicare beneficiaries. Journal of Aging and Health, 27(6), 9831002.

Kutner, L. (1969). Due process of euthanasia: The living will, a proposal. Indiana Law Journal, 44(4), 539-554.

LaFrance, S. \& Leaver, M. (2007). Healthcare decision-making legislation approved: Revisions to advance directives and a DNR law enacted. New Hampshire Bar Journal. Retrieved from https://www.nhbar.org/publications/display-journalissue.asp? $\mathrm{id}=352$

Lee, M. A., Brummel- Smith, K., Meyer, J., Drew, N., \& London, M. R. (2000). Physician orders for life- sustaining treatment (POLST): Outcomes in a PACE Program. Journal of the American Geriatrics Society, 48(10), 1219-1225.

Lopez-Acevedo, M., Havrilesky, L. J., Broadwater, G., Kamal, A. H., Abernethy, A. P., Berchuck, A., ... \& Lee, P. S. (2013). Timing of end-of-life care discussion with performance on end-of-life quality indicators in ovarian cancer. Gynecologic oncology, 130(1), 156-161.

Lowey, S.E. (2015). Nursing care at the end of life: What every clinician should know. Geneseo, NY: Open SUNY Textbooks

Lund, S., Richardson, A., \& May, C. (2015). Barriers to advance care planning at the end of life: an explanatory systematic review of implementation studies. PLOS One, 10(2).

Mack, J. W., Weeks, J. C., Wright, A. A., Block, S. D., \& Prigerson, H. G. (2010). Endof-life discussions, goal attainment, and distress at the end of life: predictors and 
outcomes of receipt of care consistent with preferences. Journal of Clinical Oncology, 28(7), 1203-1208.

Malloy, P., Paice, J., Virani, R., \& Ferrell, B. R. (2008). End-of-life nursing education consortium: 5 years of educating graduate nursing faculty in excellent palliative care. Journal of Professional Nursing, 24(6), 352-357.

Martyn, S.R. \& Jacobs, L.B. (1984). Legislating advanced directives for the terminally ill: The living will and durable power of attorney. Nebraska Law Review, 63(4), 779-809. Retrieved from http://digitalcommons.unl.edu/cgi/viewcontent.cgi?article=1949\&context=nlr

Meier, E. A., Gallegos, J. V., Thomas, L. P. M., Depp, C. A., Irwin, S. A., \& Jeste, D. V. (2016). Defining a good death (successful dying): Literature review and a call for research and public dialogue. The American Journal of Geriatric Psychiatry, 24(4), 261-271.

Michie, S., Johnston, M., Abraham, C., Lawton, R., Parker, D., \& Walker, A. (2005). Making psychological theory useful for implementing evidence based practice: A consensus approach. Quality and Safety in Health Care, 14(1), 26-33.

Myers, J. (2015). Improving the quality of end-of-life discussions. Current Opinion in Supportive and Palliative Care, 9(1), 72-76.

National Guideline Clearinghouse. (2014). Advance care planning. Retrieved from https://www.guideline.gov/summaries/summary/47803/advance-care-planning

Nauck, F., Becker, M., King, C., Radbruch, L., Voltz, R., \& Jaspers, B. (2014). To what extent are the wishes of a signatory reflected in their advance directive: A qualitative analysis. BMC Medical Ethics, 15(1), 1. 
New Hampshire General Court. (n.d.). Title X Public Health Chapter 137-J Written directives for medical decision making for adults without capacity to make health care decisions. Retrieved from http://www.gencourt.state.nh.us/rsa/html/x/137j/137-j-mrg.htm

Old, J.L. (2008). Discussing end-of-life care with your patients. Family Practice Management, 15(3), 18.

Physician Orders for Life Sustaining Treatment Paradigm. (n.d.). About POLST. Retrieved from http://www.polst.org/about-the-national-polst-paradigm/history/

Physician Orders for Life Sustaining Treatment Paradigm. (2016). National POLST paradigm. $\quad$ Retrieved from http://www.polst.org/wpcontent/uploads/2016/05/2016.05.02-POLST-State-Status.pdf

Rao, J. K., Anderson, L. A., Lin, F. C., \& Laux, J. P. (2014). Completion of advance directives among US consumers. American Journal of Preventive Medicine, 46(1), 65-70.

Riley, G. F., \& Lubitz, J. D. (2010). Long- term trends in Medicare payments in the last year of life. Health Services Research, 45(2), 565-576.

Sabatino, C. P. (2010). The evolution of health care advance planning law and policy. Milbank Quarterly, 88(2), 211-239.

Sabatino, C. P., \& Karp, N. (2011). Improving advanced illness care: The evolution of state POLST programs. Retrieved from http://assets.aarp.org/rgcenter/ppi/consprot/POLST-Report-04-11.pdf

Schickedanz, A. D., Schillinger, D., Landefeld, C. S., Knight, S. J., Williams, B. A., \& Sudore, R. L. (2009). A clinical framework for improving the advance care 
planning process: Start with patients' self- identified barriers. Journal of the American Geriatrics Society, 57(1), 31-39.

Schmidt, T. A., Zive, D., Fromme, E. K., Cook, J. N., \& Tolle, S. W. (2014). Physician orders for life-sustaining treatment (POLST): Lessons learned from analysis of the Oregon POLST Registry. Resuscitation, 85(4), 480-485.

Sessums, L. L., Zembrzuska, H., \& Jackson, J. L. (2011). Does this patient have medical decision-making capacity?. Journal of the American Medical Association, 306(4), $420-427$.

Silveira, M. J., Kim, S. Y., \& Langa, K. M. (2010). Advance directives and outcomes of surrogate decision making before death. New England Journal of Medicine, 362(13), 1211-1218.

Sorger, B. M., Rosenfeld, B., Pessin, H., Timm, A. K., \& Cimino, J. (2007). Decisionmaking capacity in elderly, terminally ill patients with cancer. Behavioral Sciences \& the Law, 25(3), 393-404.

Stajduhar, K. I., Allan, D. E., Cohen, S. R., \& Heyland, D. K. (2008). Short report: Preferences for location of death of seriously ill hospitalized patients: perspectives from Canadian patients and their family caregivers. Palliative Medicine, 22(1), 85-88.

The Conversation Project. (2013). New survey reveals 'conversation disconnect': 90 percent of Americans know they should have conversation about what they want at the end of life, yet only $30 \%$ have done so. Retrieved from http://theconversationproject.org/wp-content/uploads/2013/09/TCP-SurveyRelease_FINAL-9-18-13.pdf 
The Hospice Foundation of America. (n.d.). Being mortal. Retrieved from https://hospicefoundation.org/Home/Being-Mortal-Project

The Kaiser Family Foundation. (2016). Total number of nurse practitioners, by gender. Retrieved from http://kff.org/other/state-indicator/total-number-of-nursepractitioners-by-gender/

The National Hospice and Palliative Care of America. (n.d.) NHPCO's facts and figures hospice care in America. Retrieved from https://www.nhpco.org/sites/default/files/public/Statistics_Research/2015_Facts_ Figures.pdf

The President's Council on Bioethics. (2005). Taking care: Ethical caregiving in our aging society. Retrieved from https://bioethicsarchive.georgetown.edu/pcbe/reports/taking_care/chapter2.html Uniform Law Commission. (1994). Uniform Health-Care Decision Act. Retrieved from http://www.uniformlaws.org/shared/docs/health\%20care\%20decisions/uhcda_fina 1_93.pdf

Uniform Law Commission. (2016). Legislative fact sheet-health care decisions act. Retrieved from http://www.uniformlaws.org/LegislativeFactSheet.aspx?title=HealthCare\%20Decisions\%20Act

United States Census Bureau. (2014). QuickFacts New Hampshire. Retrieved from http://www.census.gov/quickfacts/table/RHI625214/33 
Winter, L., Parks, S. M., \& Diamond, J. J. (2010). Ask a different question, get a different answer: Why living wills are poor guides to care preferences at the end of life. Journal of Palliative Medicine, 13(5), 567-572.

Wheeler, M. S. (2016). Primary palliative care for every nurse practitioner. The Journal for Nurse Practitioners, 12(10), 647-653.

World Health Organization. (n.d.). WHO definition of palliative care. Retrieved from http://www.who.int/cancer/palliative/definition/en/

Wright, A. A., Zhang, B., Ray, A., Mack, J. W., Trice, E., Balboni, T., ... \& Prigerson, H. G. (2008). Associations between end-of-life discussions, patient mental health, medical care near death, and caregiver bereavement adjustment. The Journal of the American Medical Association, 300(14), 1665-1673.

Zeitoun, N.K. (2015, November 5). New Medicare rules will reimburse physicians for advance care planning. The Hospitalist. Retrieved from http://www.thehospitalist.org/article/new-medicare-rule-will-reimburse-physicians-for-advancecare-planning/?singlepage $=1$

Zhou, G., Stoltzfus, J., Houldin, A., Parks, S., \& Swan, B.A. (2010). Knowledge, attitudes, and practice behaviors of oncology advanced practice nurses regarding advanced care planning for patients with cancer. Oncology Nursing Forum, 37(6), 400-410. 


\section{Appendix A}

Theoretical Domains Framework

\begin{tabular}{|c|c|}
\hline $\begin{array}{c}\text { Refined Framework Domains and } \\
\text { Definition }\end{array}$ & Theoretical Constructs \\
\hline $\begin{array}{l}\text { Knowledge } \\
\text { (An awareness of the existence of } \\
\text { something) }\end{array}$ & $\begin{array}{l}\text { Knowledge (knowledge of condition/ } \\
\text { scientific rationale), Procedural knowledge, } \\
\text { Knowledge of task environment }\end{array}$ \\
\hline $\begin{array}{l}\text { Skills } \\
\text { (An ability or proficiency acquired } \\
\text { through practice) }\end{array}$ & $\begin{array}{l}\text { Skills, Skills development, Competence, } \\
\text { Ability, Interpersonal skills, Practice, Skills } \\
\text { Assessment }\end{array}$ \\
\hline $\begin{array}{l}\text { Social/ Professional Role and Identity } \\
\text { (A coherent set of behavior displayed } \\
\text { personal qualities of an individual in a } \\
\text { social or work setting) }\end{array}$ & $\begin{array}{l}\text { Professional identity, Professional role, } \\
\text { Social identity, Identity, Professional } \\
\text { boundaries, Professional confidence, Group } \\
\text { identity, Leadership, Organizational } \\
\text { commitment }\end{array}$ \\
\hline $\begin{array}{l}\text { Beliefs about capabilities } \\
\text { (Acceptance of the truth, reality, or } \\
\text { validity about an ability, talent, or } \\
\text { facility that a person can put to } \\
\text { constructive use) }\end{array}$ & $\begin{array}{l}\text { Self-confidence, Perceived competence, } \\
\text { Self-efficacy, Perceived behavioral control, } \\
\text { Beliefs, Self-esteem, Empowerment, } \\
\text { Professional confidence }\end{array}$ \\
\hline $\begin{array}{l}\text { Optimism } \\
\text { (The confidence that things will happen } \\
\text { for the best or that desired goals will be } \\
\text { attained) }\end{array}$ & $\begin{array}{l}\text { Optimism, Pessimism, Unrealistic } \\
\text { optimism, Identity }\end{array}$ \\
\hline $\begin{array}{l}\text { Beliefs about consequences } \\
\text { (Acceptance of the truth, reality, or } \\
\text { validity about outcomes of a behavior in } \\
\text { a given situation) }\end{array}$ & $\begin{array}{l}\text { Outcome expectancies, Characteristics of } \\
\text { outcome expectancies, Beliefs, Anticipated } \\
\text { regret, Consequents }\end{array}$ \\
\hline $\begin{array}{l}\text { Reinforcement } \\
\text { (Increasing the probability of a response } \\
\text { by arranging a dependent relationship, } \\
\text { or contingency, between the response } \\
\text { and a given stimulus) }\end{array}$ & $\begin{array}{l}\text { Rewards, Incentives, Punishment, } \\
\text { Consequents, Reinforcement, } \\
\text { Contingencies, Sanctions }\end{array}$ \\
\hline $\begin{array}{l}\text { Intentions } \\
\text { (A conscious decision to perform a } \\
\text { behavior or a resolve to act in a certain } \\
\text { way) }\end{array}$ & $\begin{array}{l}\text { Stability of intentions, Stages of change } \\
\text { model, Transtheoretical model/models of } \\
\text { change }\end{array}$ \\
\hline $\begin{array}{l}\text { Goals } \\
\text { (Mental representation of outcomes or } \\
\text { end states that an individual wants to } \\
\text { achieve) }\end{array}$ & $\begin{array}{l}\text { Goals (distal/proximal), Goal priority, } \\
\text { Goal/target setting, Goals } \\
\text { (autonomous/controlled), Action planning, } \\
\text { Implementation intention }\end{array}$ \\
\hline
\end{tabular}




\begin{tabular}{|l|l|}
\hline $\begin{array}{l}\text { Memory, attention and decision process } \\
\text { (The ability to retain information, focus } \\
\text { selectively on aspects of the } \\
\text { environment and choose between two or } \\
\text { more alternatives) }\end{array}$ & $\begin{array}{l}\text { Memory, Attention, Attention control } \\
\text { decision making, Cognitive overload/ } \\
\text { tiredness }\end{array}$ \\
\hline $\begin{array}{l}\text { Environmental context and resources } \\
\text { (Any circumstance of a person's } \\
\text { situation or environment that encourages } \\
\text { or discourages the development of skills } \\
\text { and abilities, independence, social } \\
\text { competence, and adaptive behavior) }\end{array}$ & $\begin{array}{l}\text { Environmental stressors, Resources/ } \\
\text { material resources, Barriers and facilitators, } \\
\text { Onvironment interaction, Salient events/ } \\
\text { critical incidents }\end{array}$ \\
\hline $\begin{array}{l}\text { Social influences } \\
\text { (Interpersonal processes that can cause }\end{array}$ & $\begin{array}{l}\text { Social pressure, Social norms, Group } \\
\text { conformity, Social comparisons, Group } \\
\text { norms, Social support, Intergroup conflict, } \\
\text { feelings, or behaviors) }\end{array}$ \\
$\begin{array}{l}\text { Power, Group identity, Alienation, } \\
\text { Modeling }\end{array}$ \\
$\begin{array}{l}\text { (A complex reaction pattern, involving } \\
\text { experiential, behavioral, and } \\
\text { psychological elements, by which the } \\
\text { individual attempts to deal with a } \\
\text { personally significant matter or event) }\end{array}$ & $\begin{array}{l}\text { Anxiety, Fear, Affect, Stress, Depression, } \\
\text { Positive/ negative affect, burnout }\end{array}$ \\
\hline $\begin{array}{l}\text { Behavioral Regulation } \\
\text { (Anything aimed at managing or } \\
\text { changing objectively observed or } \\
\text { measured actions) }\end{array}$ & $\begin{array}{l}\text { Self-monitoring, Breaking habit, Action } \\
\text { planning }\end{array}$ \\
\hline
\end{tabular}

Note: Theoretical domains and constructs table used with permission from Cane, O’Connor, \& Michie (2012). 


\section{Appendix B}

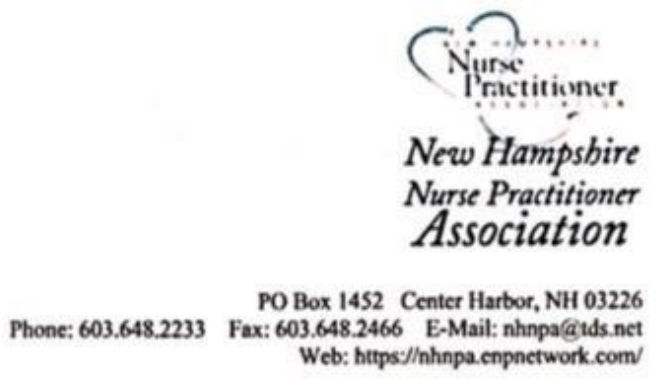

Date: June 27, 2016

Cherish Dellava

cherishclamor@gmail.com

401.486.0791

\section{Dear Cherish:}

On behalf of the New Hampshire Nurse Practitioner Association, I would like to notify you that we are delighted to assist you with your current research project. As we understand, you will be developing a survey focusing on the perspective of nurse practitioners and advanced care planning. We will be able forward your survey to our current member base of approximately 430 advanced practice registered nurses in New Hampshire. We look forward to working with you.

Sincerely,

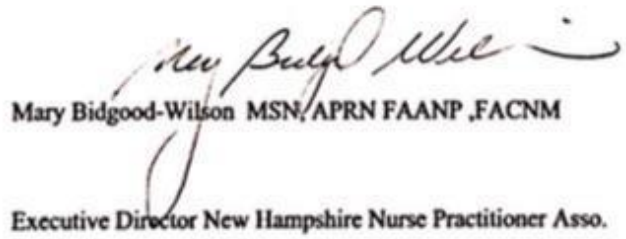




\section{Appendix C}

Recruitment Email

Dear Advanced Practice Registered Nurse,

You are being asked to volunteer in a master's major project study designed for Nurse Practitioners. The purpose of this study is to explore the perspectives of Nurse Practitioners on the barriers and facilitators of advance care planning. The Advance Care Planning Survey is an online survey. The survey will take 3 to 5 minutes to complete. A link to the survey can be found in the informational letter, a document attached to this email.

Please open the informational letter that is attached to this email and review it before taking the survey. The informational letter will describe and address the following: purpose and procedures of the study, risks, compensation, benefits, and how your information will be protected. The informational letter also contains contact information of the student researcher, faculty advisor, and the Rhode Island College Institutional Review Board.

Your participation is voluntary. If you wish to participate, please click on the survey link found at the end of the informational letter.

Thank you for your participation.

Sincerely,

Cherish Dellava, RN, BSN

Rhode Island College

cclamor_4893@email.ric.edu 


\title{
Appendix D
}

\section{INFORMATIONAL LETTER/CONSENT DOCUMENT}

\author{
Rhode Island College
}

Nurse Practitioner Perspectives on the Barriers and Facilitators of Advance Care Planning

You are being asked to volunteer in a master's major project study on Advance Care Planning. You are being asked to participate because you are a nurse practitioner and we would like to get your perspective on the barriers and facilitators of advance care planning.

Cherish Dellava, a graduate student of Rhode Island College and faculty advisor, Linda Dame DNP, FNP-BC will be doing this study.

\section{Why this Study is Being Done (Purpose)}

The purpose of this study is to explore the perspectives of Nurse Practitioners on the barriers and facilitators of advance care planning.

\section{What You Will Have to Do (Procedures)}

If you choose to participate in this study, we will ask you to:

$\square$ Complete an anonymous, one-time, online survey that you can access by clicking on the survey link found at the end of this section. The survey will take approximately 3 to 5 minutes to complete.

$\square$ The survey includes 3 sections. The demographic data section includes age, gender and level of nursing education. Professional data questions include: hours of practice every week; practice setting; years of practice; and education on end- of-life care issues. The practice data section will ask you to rate barriers and facilitators of advance care planning.

Click on the survey link found at the end of this letter and then click submit once you have completed the survey.

\section{$\underline{\text { You Will Be Paid (Compensation) }}$}


There will be no financial compensation for participation.

\section{$\underline{\text { Risks or Discomforts }}$}

This study has minimal risk. Some questions may be sensitive or upsetting to some participants. We think that these questions are similar to the kinds of things you talk about with your family or colleagues. You can skip questions or withdraw from the survey at any time.

\section{Benefits of Being in the Study}

Being in this study will not benefit you directly.

\section{Deciding Whether to Be in the Study}

Being in the study is your choice to make. Nobody can force you to be in the study. You can choose not to be in the study, and nobody will hold it against you. You can change your mind and quit the study at any time, and you do not have to give a reason. If you decide to quit later, nobody will hold it against you.

\section{How Your Information will be Protected}

Because this is a research study, results will be summarized across all participants and shared in reports that we publish and presentations that we give. Your name will not be used in any reports. We will take several steps to protect the information you give us so that you cannot be identified. The survey settings are set so that the responses cannot be traced to a participant. The survey will not ask for your name or contact information. The survey results will be kept in a password-protected file, and seen only by myself and other researchers who work with me. If there are problems with the study, the records may be viewed by the Rhode Island College review board responsible for protecting the rights and safety of people who participate in research. The information will be kept for a minimum of three years after the study is over, after which it will be destroyed.

\section{Who to Contact}

You can ask any questions you have now. If you have any questions later, you can contact myself, Cherish Dellava at cclamor_4893@email.ric.edu or 401-486-0791. You can also contact Dr. Linda Dame at ldame@ric.edu, or by phone at 401-456-9668

If you think you were treated badly in this study, have complaints, or would like to talk to 
someone other than the researcher about your rights or safety as a research participant, please contact Cindy Padula at IRB@ ric.edu, by phone at 401-456-9720.

You can keep a copy of this form for your records.

\section{$\underline{\text { Statement of Consent }}$}

I have read and understand the information above. I am choosing to participate in the study "Nurse Practitioner Perspectives on the Barriers and Facilitators of Advance Care Planning." I can change my mind and quit at any time, and I don't have to give a reason. I have been given answers to the questions I asked, or I will contact the researcher with any questions that come up later. I am at least 18 years of age.

Click here to take the Advance Care Planning Survey 


\section{Appendix E}

\section{Advance Care Planning Survey}

\section{Section 1: Demographics}

1. What is your age in years?
a. $20-29$
b. $30-39$
c. $40-49$
d. 50-59
e. $60-65$
f. $>65$

2. What is your gender?
a. Female
b. Male

3. Please indicate your highest level of nursing education?
a. BS
b. MS
c. $\mathrm{PhD} / \mathrm{EdD}$
d. DNP

\section{Section 2: Professional Data}

4. Which of the following best describes how many hours you practice weekly in your clinical position?
a. $\quad<20$ hrs per week
b. $21-30 \mathrm{hrs}$
c. $31-40 \mathrm{hrs}$ 
d. $>40$ hrs

5. Which of the following describes your current practice setting?
a. Physician office/community based outpatient
b. Hospital Outpatient
c. Community
d. Hospital Inpatient
e. Nursing Home and other long-term care
f. Other

6. Please identify your certification specialty:
a. Family
b. Adult/Gerontology
c. Pediatric
d. Women's Health
e. Primary Care
f. Other: please specify

7. Number of years in practice as an NP:
a. $0-5$
b. 6-15
c. $16-25$
d. > 25 years

8. Was End-of-Life care covered in your formal NP education?
a. Yes
b. No

9. Have you ever taken continuing education courses or seminars in End-of- Life care issues? 

a. Yes
b. No

10. Are you aware of the federal mandate to provide Advance Care Planning (ACP) discussions to patients?
a. Yes
b. No

\section{Section 3: Practice Data}

11. To what extent might the following be a barrier to ACP discussions in your practice as an NP? Please answer according to scale.

$0=$ not a barrier $1=$ least likely $5=$ most likely.
a) Lack of time
$\begin{array}{llllll}0 & 1 & 2 & 3 & 4 & 5\end{array}$
b) Staff shortage
$\begin{array}{llllll}0 & 1 & 2 & 3 & 4 & 5\end{array}$
c) Length of appointment
$\begin{array}{llllll}0 & 1 & 2 & 3 & 4 & 5\end{array}$
d) Type of appointment
$\begin{array}{llllll}0 & 1 & 2 & 3 & 4 & 5\end{array}$
e) Lack of education/training
$\begin{array}{llllll}0 & 1 & 2 & 3 & 4 & 5\end{array}$
f) Lack of available forms
$\begin{array}{llllll}0 & 1 & 2 & 3 & 4 & 5\end{array}$
g) Lack of electronic medical recor

$\begin{array}{llllll}0 & 1 & 2 & 3 & 4 & 5\end{array}$
h) Lack of leadership support
$\begin{array}{llllll}0 & 1 & 2 & 3 & 4 & 5\end{array}$
i) Discomfort with topic
$\begin{array}{llllll}0 & 1 & 2 & 3 & 4 & 5\end{array}$
j) Concern about upsetting patient $\quad \begin{array}{llllll}0 & 1 & 2 & 3 & 4 & 5\end{array}$
k) Other: please specify

12. To what extent might the following be a facilitator to ACP discussions in your NP practice? Please answer according to scale.

$0=$ not a facilitator $1=$ least likely $5=$ most likely.
a) Length of appointment
$\begin{array}{llllll}0 & 1 & 2 & 3 & 4 & 5\end{array}$
b) Adequate staff
$\begin{array}{llllll}0 & 1 & 2 & 3 & 4 & 5\end{array}$ 


$\begin{array}{lllllll}\text { c) Type of appointment } & 0 & 1 & 2 & 3 & 4 & 5 \\ \text { d) Having electronic medical record } & 0 & 1 & 2 & 3 & 4 & 5 \\ \text { e) Availability of forms } & 0 & 1 & 2 & 3 & 4 & 5 \\ \text { f) Support of leadership } & 0 & 1 & 2 & 3 & 4 & 5 \\ \text { g) Long term relationship with patient } & 0 & 1 & 2 & 3 & 4 & 5 \\ \text { h) Understanding of the forms } & 0 & 1 & 2 & 3 & 4 & 5 \\ \text { i) Comfort with topic } & 0 & 1 & 2 & 3 & 4 & 5 \\ \text { j) Previous training/education } & 0 & 1 & 2 & 3 & 4 & 5 \\ \text { k) Personal experience } & 0 & 1 & 2 & 3 & 4 & 5 \\ \text { 1) } & \text { Other: please specify__ } & & & & & \end{array}$

13. Is there anything else regarding barriers or facilitators in your practice that you think I should know about? 